\title{
Distribution network reconfiguration considering DGs using a hybrid CS-GWO algorithm for power loss minimization and voltage profile enhancement
}

\author{
Pujari Harish Kumar' ${ }^{1}$, Mageshvaran Rudramoorthy ${ }^{2}$ \\ ${ }^{1,2}$ School of Electrical Engineering, Vellore Institute of Technology, India.
}

\begin{tabular}{l} 
Article Info \\
\hline Article history: \\
Received Oct 8, 2021 \\
Revised Nov 26, 2021 \\
Accepted Dec 14, 2021 \\
\hline
\end{tabular}

\section{Keyword:}

Distributed generator, Distribution network reconfiguration, Grey wolf algorithm, Cuckoo search algorithm, Power loss reduction, Voltage profile.

\begin{abstract}
This paper presents an implementation of the hybrid Cuckoo search and Grey wolf (CS-GWO) optimization algorithm for solving the problem of distribution network reconfiguration (DNR) and optimal location and sizing of distributed generations (DGs) simultaneously in radial distribution systems (RDSs). This algorithm is being used significantly to minimize the system power loss, voltage deviation at load buses and improve the voltage profile. When solving the high-dimensional datasets optimization problem using the GWO algorithm, it simply falls into an optimum local region. To enhance and strengthen the GWO algorithm searchability, CS algorithm is integrated to update the best three candidate solutions. This hybrid CS-GWO algorithm has a more substantial search capability to simultaneously find optimal candidate solutions for problems. The obtained test results for the 33-bus system show that minimization of active power loss was enhanced by $74.73 \%, 73.35 \%$, and $80.37 \%$ for light, nominal, and heavy load conditions, respectively, and similarly for 69 - bus system is $81.50 \%, 84.74 \%$, and $88.86 \%$. The minimum voltage value for 33 - bus system under nominal load condition was enhanced from 0.9130 p.u to 0.9865 p.u and similarly for the 69-bus system is 0.9094 p.u to 0.9842 p.u. Respectively. Furthermore, to validate the effectiveness and performances of the proposed hybrid CS-GWO algorithm with existing methods is presented. This method is tested and evaluated for standard IEEE 33-bus and 69-bus RDSs by considering different scenarios. Finally, the comparative analysis shows that the proposed algorithm was more efficient in minimizing power losses and enhancing the voltage profile of the system.
\end{abstract}

Copyright (C) 2021 Institute of Advanced Engineering and Science. All rights reserved.

\section{Corresponding Author:}

Mageshvaran Rudramoorthy, School of Electrical Engineering, Vellore Institute of Technology, Vellore, Tamil Nadu, India Email: rmageshvaran@vit.ac.in

\section{INTRODUCTION}

The distribution system (DS) is the final stage in the construction and planning electrical power system, which delivers the power between the transmission and end-user consumer. Transmission networks operate in loops/radial structures and distribution networks always operate in radial structure to reduce the short circuit currents. Distribution network reconfiguration (DNR) is defined as the process of varying the topological arrangement of distribution feeders by changing the open/closed status of sectionalizing and tie switches concerning system constraint and satisfying the operator objectives. The most common practice methods used by researchers widely for power loss (PL) reduction and voltage profile improvement in DS is network reconfiguration (NR) and DGs integration in DS [1,2]. Generally, distribution networks/systems are reconfigured to minimize the system PL and relieve overload. However, dynamic loads in the system may increase total system loads; it may be higher than its generation capacity sometimes, making it difficult to relieve the load on the feeders. Due to this problem system voltage profile may not be enhanced to the required 
level. Therefore, to meet the desired level of load demand, DGs have to be installed to enhance voltage profile and supply continuous power to customers.

The main objectives of DNR were to reduce system PL, load balancing and improve voltage profile and voltage stability of the system. Furthermore, many researchers have implemented optimization techniques such as Analytical, Heuristic, Meta-heuristic, AI and Hybrid methods to minimize system PL. These methods may also be used to improve system power transmission reliability and provide a continuous power supply for the varying load. Analytical techniques use distinct switching and sensitivity computation methods for changing the network's topology structure by closing and opening switches in a loop. Similarly, Metaheuristic, AI techniques and hybrid methods implemented by researchers are also widely used for solving network reconfiguration and DGs allocation problems simultaneously for minimization of system PL and voltage profile improvement. The drawback of metaheuristics methods is it takes more computation time and iterations to search and generate an optimal solution for the problem considered compared to analytical techniques. On the other hand, these methods can handle large datasets' complex issues and solve single/multi-objective functions with high accuracy and convergence.

Merlin and Back [3], in the year 1975 have implemented a discrete branch and bound technique to solve the DNR problem to minimize feeder loss by satisfying the system constraints. Civanlar et al. [4] have proposed a switch exchange method to solve the NR problem and developed a simple formula to estimate PL reduction for a particular topology structure obtained by opening and closing a specific switch in loops. In the past decade of literature, many metaheuristic techniques have been proposed by the researchers to find the optimal solution for the DNR problem separately without DGs allocation, with an aim to minimize active PL and enhance the voltage profile of system. Some of the most popularly used metaheuristic algorithms to solve DNR problem alone with different objective functions are listed as Refined genetic algorithm[5], Harmony search algorithm[6], Minimum current circular-updating mechanism method[7], Discrete PSO algorithm[8], Improved adaptive imperialist competitive algorithm[9], Catfish PSO algorithm[10], Fireworks algorithm[11], Enhanced genetic algorithm[12], NSGA-II algorithm[13], Cuckoo search algorithm[14], Genetic algorithm with varying population size[15], Runner-root algorithm[16], Biased random key genetic algorithm[17], Binary PSO algorithm[18], Modified culture algorithm[19], Feasibility-preserving evolutionary optimization[20], graphically-based network reconfiguration[21]. Moreover, this algorithm needs many control parameters to be tuned for each problem to obtain an optimal solution. Therefore, these approaches have been used extensively to solve large-scale complex problems to obtain better solutions.

Besides, various research studies in the literature have made a tremendous effort to find the optimal location and sizing of DGs in the DS by applying different approaches with an aim to improve the performances and voltage profile of DS. DGs allocation in an optimal location and suitable sizes may minimize active power loss and improve the system voltage profile and power quality. Many meta-heuristic algorithms have been introduced to solve DG allocation problems for last decades, such as genetic algorithm and particle swarm optimization [22], modified bacterial foraging optimization algorithm [23], analytical approach [24], invasive weed optimization algorithm [25], quasi-oppositional teaching-learning based optimization [26], intelligent water drop algorithm [27], Krill herd algorithm [28], Flower Pollination algorithm [29], Shuffled Bat algorithm [30], Stud Krill herd Algorithm [31], hyper-spherical search algorithm [32], one rank cuckoo search algorithm [33], symbiotic organism search-based method [34], stochastic fractal search algorithm [35], combined evolutionary algorithm [36], mutated salp swarm algorithm [37], Multi-Objective Hybrid Teaching-Learning Based Optimization-Grey Wolf Optimizer [38], coyote optimization algorithm (COA) and electrical transient analyzer program (ETAP)[39], improved spotted hyena algorithm [40]. These methods are easy to implement and widely used in the DS to obtain a global optimum solution with less computation time. In this context, a hybrid CS-GWO algorithm is used to find the optimal allocation of DGs and suitable sizes to minimize active PL and improve voltage profile. This algorithm's obtained results are better than various optimization methods in literature such as HSA, GA, RGA, FWA and UVDA.

\section{RELATED WORKS}

In past works, it is observed that DNR and optimal allocation of DGs in RDSs are generally studied independently. Integration of these sub-problems together and solving them concurrently may lead to more advantages to DS operators. There are very few works in the literature dealing with the DNR and optimal allocation and sizing of DGs simultaneously for minimizing active PL. Performing DNR using available switches in loops can reduce PL, improve voltage regulation, relieve feeder loading, and improve system reliability. Implementing DNR and DG allocation simultaneously in DS has been more effective for active PL reduction and voltage profile improvement in RDSs than other methods. This method may also enhance the system performance, quality and reliability. In this paper, both DNR and DG allocation problem is solved simultaneously by applying a hybrid CS-GWO algorithm to obtain a desired optimal solution. 
Various effective optimization algorithm have been implemented by researchers in literature for solving DNR and DGs allocation problem simultaneously are listed as: Harmony search algorithm [41], hypercube ant colony optimization algorithm [42], Fireworks Algorithm [43], modified plant growth simulation algorithm [44], adaptive cuckoo search[45], binary particular swarm optimization algorithm [46], enhanced evolutionary algorithm [47], uniform voltage distribution based constructive reconfiguration algorithm[48], discrete artificial bee colony algorithm [49], Harmony search algorithm (HSA) and particle artificial bee colony algorithm (PABC) [50], hybrid Grey Wolf Optimizer (GWO)-Sine Cosine Algorithm (SCA)[51], hybrid Particle Swarm Optimizer (PSO)-ant colony optimization (ACO) [52], comprehensive teaching-learning-based optimization algorithm [53], Grey Wolf Optimizer (GWO) and Particle Swarm Optimizer (PSO)[54], Strength Pareto Evolutionary Algorithm 2 [55], adaptive shuffled frogs leaping algorithm [56], Particle swarm optimization (PSO) and Dragonfly algorithm (DA) [57], Stochastic fractal search algorithm [58], Mixed Particle Swarm Optimization [59], Symbiotic Organism Search Algorithm [60], Equilibrium optimization algorithm [61], Harris Hawks Optimization [62], Meta-heuristic matrix moth-flame algorithm [63], Bacterial Foraging with Spiral Dynamic (BF-SD) algorithm [64], chaotic stochastic fractal search algorithm[66], Modified Selective particle swarm optimization (SPSO) method[73], Grasshopper optimization algorithm (GOA)[74], Grid based Multi-Objective Harmony Search Algorithm (GrMHSA)[75], Modified Whale Optimization (MOWOA) algorithm and fuzzy decision-making method[77], Fuzzy Expert System (FES) method[78], Manta-Ray Foraging Optimization (MRFO) algorithm[79], Rider Optimization Algorithm[80]. The summary of recently published works on DNR considering DG problems in the literature above discussed is provided clearly in Appendix Table A1.

Researchers in the past and recently published works have already implemented various methods for solving network reconfiguration problems and DGs placement in DS separately, considering some constraints and assumptions. But few works have been published in solving DNR problems simultaneously considering DGs. So, we have focused on this area of research to work using hybrid metaheuristics algorithms to solve DNR problems considering DGs and Renewable energy sources and capacitor placement to obtain an optimal solution within a short duration of convergence time.

The above algorithms mentioned by researchers have also yielded better results. Still, a minor variation will be in the convergence time of the solution depending on algorithm performances and control parameters. For example, it is observed that the Grey wolf optimizer (GWO) algorithm updates the positions of wolves by random search, and the highest fitness value is computed. Thus, the random search's fitness value may lead to weak global search ability and fall easily into the optimum local region, mainly when performed on large-dimensional data sets. On the other hand, the cuckoo search (CS) algorithm is used to update the nest's positions using a levy flight search to avoid this problem. This search method can quickly find the random best positions of birds very rapidly by changing birds' directions with sudden turns.

Due to this CS algorithm feature, the solution obtained can quickly jump from the current area to other areas to get an optimal solution less competitively. Based on this advantage, the CS algorithm is integrated into the GWO algorithm to obtain a better optimal solution for optimization problems.

In this context, the significant contribution of this paper is highlighted as follows:

- The application of a hybrid CS-GWO algorithm is introduced to solve the DNR problem considering DGs allocation simultaneously for the first time.

- In this context, voltage deviation at load buses and percentage voltage improvement are also calculated.

- The proposed method is applied, tested successfully on standard IEEE 33-bus and 69-bus systems for different scenarios.

- Further, the proposed method's results are compared with other metaheuristic algorithms existing in the literature (such as FWA, RGA, GA, HSA, ACSA, UVDA, MPGSA, SFS, EOA, IEOA) to evaluate the performance of the algorithm.

The remaining of the paper is arranged according to the following: Section 2, Describe the problem formulation. The implementation of the hybrid CS-GWO algorithm and pseudocode along with a flowchart to solve the DNR problem considering DGs simultaneously is presented in Section 3. Section 4 explains test results and a comparative analysis of the proposed technique with existed techniques were discussed on different IEEE test systems considered. The study is concluded in Section 5.

\footnotetext{
Nomenclature

$P_{\text {Loss }}(m, m+1):$ Loss in the line connecting buses $m$ and $m+1$

$P_{T L, L o s s} \quad$ : Total active power loss of the DS
} 
$P^{\prime}{ }_{\text {Loss }}(m, m+1)$ : Loss in the line connecting buses $m$ and $m+1$ after DNR

$P_{T L, \text { Loss }}^{\prime} \quad$ : Total active power loss of the DS after DNR

$\Delta P_{\text {Los }}^{R E} \quad:$ Net power loss before and after DNR

$\triangle P_{\text {LosS }}^{D G} \quad$ : Power loss due to DG installation

$R_{m} \quad:$ resistance of the line section between buses $m$ and $m+1$

$X_{m} \quad$ : reactance of the line section between buses $m$ and $m+1$

$\Delta V_{D} \quad$ : Voltage deviation al load buses

$V_{m} \quad:$ Voltage at bus $m$

$P_{m} \quad$ : Real power flowing out of bus $m$

$P_{m}^{\prime} \quad$ : Real power flowing out of bus $m$ after DNR

$Q_{m} \quad$ : Reactive power flowing out of bus $m$

$Q_{m}^{\prime} \quad$ : Reactive power flowing out of bus $m$ after DNR

$V_{m}^{\prime} \quad:$ Voltage at bus $m$ after DNR

\section{PROBLEM FORMULATION}

The problem of DNR and optimal allocation of DGs simultaneously is to find the optimal radial structure of the network and the best location and sizing of DGs to minimize total active power loss, voltage deviation and improve the voltage profile of DS. In this work, five different scenarios were considered to solve the DNR problem considering DG installation simultaneously in order to estimate the effectiveness of the proposed hybrid CS-GWO algorithm.

\subsection{Objective functions}

The main objective of this work is to minimize the active PL, voltage deviation and improve voltage profile of the system considering DGs while satisfying all the system operating constraints.

Mathematically, the DNR problem considering DGs installation simultaneously is formulated as follows:

$$
\mathrm{f}=\min .(\mathrm{X}+\mathrm{Y})
$$

Where, $\mathrm{X}=\left(\Delta P_{\text {Loss }}^{R E}+\Delta P_{\text {Loss }}^{D G}\right)$ and $\mathrm{Y}=\Delta V_{D} \quad\left(\Delta V_{D}=\right.$ Voltage deviation at load buses $)$

PL in the DS is real and reactive power. In a balanced RDS, which has $m$ branches, the power loss connecting buses $m$ and $m+1$ were calculated using Equation 2 [65].

$$
P_{\text {Loss }}(m, m+1)=R_{m} * \frac{\left(P_{m}^{2}+Q_{m}^{2}\right)}{\left|V_{m}\right|^{2}}
$$
Equation (3)

The total active power loss, $P_{T L, L o s s}$ of DS is calculated by summating losses in all branches using

$$
P_{T L, L o s s}=\sum_{m=1}^{n} P_{\text {Loss }}(m, m+1)
$$

\subsection{Reduction of power loss using DNR}

DNR is a technique used for finding the best possible network topology of the DS that will minimize the PL. Simultaneously, specified operating constraints such as the current capacity of the feeder, system voltage profile, and radiality structure of the DS must be satisfied. The total PL of a line section linking busses between $m$ and $m+1$ after the DNR is calculated using Equation (4).

$$
P_{T L, \text { Loss }}^{\prime}=\sum_{m=1}^{n} P_{\text {Loss }}^{\prime}(m, m+1)
$$

where $P_{T L, \text { Loss }}^{\prime}$ Represents the summation of losses in all branches after the accomplishment of DNR, written as in equation (5).

$$
P_{\text {Loss }}^{\prime}(m, m+1)=R_{m}^{\prime} * \frac{\left(P_{m}^{\prime 2}+Q_{m}^{\prime 2}\right)}{\left|V_{m}^{\prime}\right|^{2}}
$$

The net PL reduction $\Delta P_{\text {LosS }}^{R E}$ In DS are computed using Equation (6), i.e., the difference of power loss value before and after DNR.

$$
\Delta P_{\text {LosS }}^{R E}=\sum_{m=1}^{n} P_{T L, L o s S}(m, m+1)-\sum_{m=1}^{n} P_{T L, L o s S}^{\prime}(m, m+1)
$$

\subsection{Reduction of power loss using DG installation}

Installing DGs in DS at the optimal location and proper size results in several advantages: reducing line losses, peak demand shaving, improving voltage profile, reducing environmental impacts, and reducing the burden on lines. Consider an RDS with $M_{L}$ branches, DG is located at node $m$, and $\gamma$ be set of branches 
linking the source and node $m$. Let us assume that the DG generate active power $\left(P_{G}\right)$ to the system, and reactive power $\left(Q_{G}\right)$ supplied or consumed from the system depending upon the source of the DG. Thus, real power and reactive current flows in the system will alter the apparent power components of the present branch set.

Total apparent power at $m^{\text {th }}$ node is calculated using Equation (7).

$$
S=S_{D m}=\sum\left(P_{D m}+j Q_{D m}\right) m=1,2,3 \ldots . n
$$

And the current at $m^{\text {th }}$ node was computed using Equation (8).

$$
I_{D}=I_{D m}^{\text {without } D G}=\left(\frac{S_{D m}}{V_{m}}\right)^{*}
$$

To integrate the DG model in the network, the apparent power demand at $m^{\text {th }}$ node, where a DG unit is located is obtained using the Equations (9)

$$
P_{D m}^{\text {with } D G}=P_{D m}^{\text {without } D G}-P_{G m}^{D G}
$$

The DG power at $m^{\text {th }}$ node was calculated using Equation (10).

$$
S_{D G m}=\sum\left(P_{G m}^{D G} \pm j Q_{G m}^{D G}\right) \quad m=1,2,3 \ldots \ldots \ldots
$$

Then the total new apparent power at $m^{\text {th }}$ node was calculated using Equation (11).

$$
[S]=\left[S_{D m}\right]-\left[S_{D G m}\right]
$$

The new current at $m^{\text {th }}$ node is computed using Equation (12).

$$
I_{D}=I_{D m}^{\text {with } D G}=\left(\frac{S_{D m}-S_{D G m}}{V_{m}}\right)^{*}
$$

By using the new current $I_{D}$ Obtained from Equation (12) and the power losses reduction due to DG installation were calculated using Equation (13).

$$
\Delta P_{\text {Loss }}^{D G}=\sum I_{D}^{2} * R_{m}
$$
calculated as

The total power loss reduction due to DNR considering DGs installation simultaneously in RDS is

$$
\mathrm{X}=\left(\Delta P_{\text {LosS }}^{R E}+\Delta P_{\text {LosS }}^{D G}\right)
$$

\subsection{Voltage deviation at load buses}

The voltage deviation $\left(\Delta V_{D}\right)$ of the network structure is computed using the eq. (15) as [66]:

$$
\Delta V_{D}=V_{\text {refe }}-V_{\text {min }}
$$

Where $V_{\text {refe }}$ : represents the prespecified voltage magnitude at load bus $m\left(V_{\text {refe }}=1.0\right.$ p.u $)$ and $V_{\min }$ : represents minimum bus voltage

\section{- Constraints}

Considering the DNR problem, the equality and inequality constraints are;

a. Voltage value should be within the specified limits for each bus:

$$
V_{\min } \leq\left|V_{m}\right| \leq V_{\max }
$$

where $V_{\min }$ and $V_{\max }$ represents the minimum and maximum bus voltages.

b. Current value should be within specific limits at each line:

$$
\left|I_{m, m+1}\right| \leq\left|I_{m, m+1, \max }\right|
$$

where $I_{m, m+1}$ represents the current between busses $m$ and $m+1$.

c. The DG units should be sized within specific limits:

$$
\begin{gathered}
P_{D \text { m, min }} \leq P_{D m} \leq P_{D \text { m, max }} \\
Q_{D m, \min } \leq Q_{D m} \leq Q_{D \text { m, max }}
\end{gathered}
$$

where $P_{D m, \min }$ and $P_{D m, \max }$ represents the minimum and maximum power provided by DG.

d. The total power generation of the system is

$$
\sum_{m=1}^{n} P_{D m} \leq \sum_{m=1}^{n}\left(P_{m}+P_{\text {Loss }(m, m+1)}\right)
$$

e. Network must be radial structure and all loads must be supplied power after DNR.

\section{Proposed Hybrid Cuckoo Search-Grey wolf algorithm for distribution network reconfiguration}

\subsection{Grey wolf optimizer $(G W O)$}

Seyedali Mirjalili and Andrew Lewis implement the GWO algorithm to solve various optimization problems in different fields [67]. This algorithm performs the common behaviour of the grey wolves (GWs) in 
cooperatively hunting their prey. It is a large-scale search method centered on three optimal samples. This algorithm's main motivation is the social leadership hierarchy and the hunting mechanism of GWs in nature. Different forms of GWs used to simulate the hierarchy of leadership are alpha $(\alpha)$, beta $(\beta)$, and delta $(\delta)$, and omega $(\omega)$. GW's hunting process is as follows; Stage 1: Includes activities like Tracking, chasing and approaching the prey. Stage 2: Consists of activities like Pursuing, encircling, and harassing the prey until it stops moving. And the final step is attacking the prey.

\subsubsection{Mathematical model and algorithm}

The mathematical models of the GWO algorithm are stated as follows;

(1). Social hierarchy of GWO- In this hierarchy, an appropriate solution is considered to be alpha $(\alpha)$, beta $(\beta)$, and delta $(\delta)$ are regarded as the three best solutions, respectively. Assume omega $(\omega)$ is the remaining candidate solution. In this algorithm, hunting (optimization) is handled by alpha $(\alpha)$, beta $(\beta)$, and delta $(\delta)$. Omega $(\omega)$ wolves move accordingly to alpha $(\alpha)$, beta $(\beta)$, and delta $(\delta)$.

(2). Encircling Prey- GWs encircle prey during hunting. Equation (21) to Equation (27) is used for mathematically modeling the encircling behaviour of the GWs

$$
\begin{aligned}
& \vec{D}=\left|\vec{C} \cdot \overrightarrow{X_{p}}(t)-\vec{X}(t)\right| \\
& \vec{X}(t+1)=\overrightarrow{X_{p}}(t)-\vec{A} \cdot \vec{D}
\end{aligned}
$$

where $t$ denotes the current iteration, $\vec{X} \& \overrightarrow{X_{p}}$ represent the position vector of the GW and the prey, and $\vec{A}, \vec{C}$ represents coefficient vectors.

- The $\vec{A}, \vec{C}$ vectors were determined by Equations (23) and (24).

$$
\begin{aligned}
& \vec{A}=2 \vec{a} \cdot \overrightarrow{r_{1}}-\vec{a} \\
& \vec{C}=2 \cdot \overrightarrow{r_{2}}
\end{aligned}
$$

where the components $\vec{a}$ which is linearly reduces from 2 to 0 throughout the repetition process and $\overrightarrow{r_{1}}$ and $\overrightarrow{r_{2}}$ denotes the arbitrary vectors $[0,1]$. Using Equations (21) and (22), the GW will update its position in any random location in the space around the prey.

$c)$. Hunting- GWs can recognize and encircle the location of prey, and alpha regularly guides the hunting process. Beta $(\beta)$ and delta $(\delta)$ may occasionally participate in hunting. This process is mathematically simulated by considering that alpha $(\alpha)$, beta $(\beta)$, and delta $(\delta)$ have provided better info about the potential location of the prey. Alpha $(\alpha)$, beta $(\beta)$, and delta $(\delta)$ are optimal solutions obtained so far during the process. The objective function in the problem is prey. Omega $(\omega)$ wolf's solution will update their location, according to the $\alpha, \beta$, and $\delta$ locations. The hunting process is formulated using Equations (25) and (26).

$$
\begin{gathered}
\overrightarrow{D_{\alpha}}=\left|\overrightarrow{C_{1}} \cdot \overrightarrow{X_{\alpha}}-\vec{X}\right|, \overrightarrow{D_{\beta}}=\left|\overrightarrow{C_{2}} \cdot \overrightarrow{X_{\beta}}-\vec{X}\right|, \overrightarrow{D_{\delta}}=\left|\overrightarrow{C_{3}} \cdot \overrightarrow{X_{\delta}}-\vec{X}\right| \\
\overrightarrow{X_{1}}=\overrightarrow{X_{\alpha}}-\overrightarrow{A_{1}} \cdot\left(\overrightarrow{D_{\alpha}}\right), \quad \overrightarrow{X_{2}}=\overrightarrow{X_{\beta}}-\overrightarrow{A_{2}} \cdot\left(\overrightarrow{D_{\beta}}\right), \overrightarrow{X_{3}}=\overrightarrow{X_{\delta}}-\overrightarrow{A_{3}} \cdot\left(\overrightarrow{D_{\delta}}\right)
\end{gathered}
$$

where $\overrightarrow{D_{\alpha}}, \overrightarrow{D_{\beta}}$ and $\overrightarrow{D_{\delta}}$ are the position vectors of the GWs in the population w.r.t $\alpha, \beta$, and $\delta$ wolves. The $\overrightarrow{C_{1}}, \overrightarrow{C_{2}}$ and $\overrightarrow{C_{3}}$ were the generated arbitrary numbers in the range $[0,2], \vec{X}$ is the search agents, i.e., population, $\overrightarrow{X_{\alpha}}, \overrightarrow{X_{\beta}}$ and $\overrightarrow{X_{\delta}}$ were the best search agents related to the optimal solutions. $\overrightarrow{A_{1}}, \overrightarrow{A_{2}}$ and $\overrightarrow{A_{3}}$ were arbitrary numbers that depend on the $\vec{a}$.

The encircling behaviour is implied to obtain the new positions of GWs using Equation (27).

$$
\vec{X}(t+1)=\frac{\left(\overrightarrow{X_{1}}+\overrightarrow{X_{2}}+\overrightarrow{X_{3}}\right)}{3}
$$

Finally, alpha $(\alpha)$, beta $(\beta)$, and delta $(\delta)$ predict the prey's location, and the remaining wolves randomly change their position around the prey. When the prey stops moving hunting, the process is ended. Alpha $(\alpha)$, beta $(\beta)$, and delta $(\delta)$ wolves predict the feasible location of the prey throughout iterations. The $\vec{a}$ is gradually reduced from 2 to 0 to make emphatic exploration and characteristics of the algorithm. Every 
candidate solution updates its distance from the prey. If $|\vec{A}|>1$, Candidate solutions move towards diverging from the prey. If $|\vec{A}|<1$ converge near the prey. Finally, the algorithm comes to an end with satisfaction.

\subsection{Integration GWO with Cuckoo search algorithm (CS)}

Yang and Deb have proposed implementing a meta-heuristic algorithm known as the cuckoo search algorithm to obtain an optimal solution using a minimum no. of parameters for various optimization problems [68]. This algorithm is mainly inspired by the obligate brood parasitism of some cuckoo species. This species lay their eggs in the nests of other host birds of different species. This algorithm is combined with the unique nesting way of cuckoo birds and levy flight behaviour of birds. The levy flight style is a common feature of flight behaviours for several animals and insects. This flight style performs a smaller movement range, but it may have a minimum probability of broad range jump and vary from the activities' mean value. Due to this CS algorithm jumps out of the optimum local region.

Levy flights perform random walks in different directions, and step lengths are obtained using the levy distribution function. These Levy flights are represented by a series of straight flights, proceeded by quick turns. Levy flights are more competent in finding large-scale search areas due to the deviation of species direction much faster when compared to traditional random walks. Using the levy flight search in the cuckoo search algorithm may reduce the number of iterations in algorithm execution. And computation time to obtain an optimal solution may be reduced compared to a standard random walk.

"The CS algorithm implementation is done based on the rules explained as follow:

- Cuckoo birds select nests randomly and they only place one egg at once.

- Next, the best nests will persist in being the next generations.

- Further, the number of bird nests and the probability of egg discover are fixed. Suppose the host bird finds an outsider bird's egg. Then the host bird will leave the nest and create a new one."

The nests are updated according to the following equations during the iteration process by satisfying the above rules.

$$
X_{i}(t+1)=x_{i}(t)+\alpha \oplus \operatorname{Levy}(\lambda), i=1,2,3, \ldots . n
$$

Where the product $\oplus$ denotes entry-wise multiplication. $X_{i}(t+1)$ represents new solutions for cuckoo, $i . x_{i}(t)$ represents the current solutions. Since $\alpha>0$ controls the step size and is set to 1 . The following probability distribution equation provides the Levy-flight:

$$
\operatorname{Levy}(\lambda)=t^{-\lambda}, 1<\lambda \leq 3
$$

Hence, this algorithm may search solutions widely in space effectively because its step length varies with short distance finding and random long-distance walking.

\subsection{Implementation of Hybrid CS-GWO for DNR and DG allocation simultaneously}

It is observed that the GWO algorithm updates the positions of wolves using equation (27) by randomly search and the highest fitness value is computed. Thus, the random search's fitness value may lead to weak global search ability and fall easily into the optimum local region, mainly when performed on largedimensional data sets. The CS algorithm updates the nest's positions using a levy flight search to avoid this problem. This search method can quickly find the random best positions of birds very rapidly by changing birds' directions with sudden turns. Furthermore, the solution obtained can soon jump from the current area to other areas to get an optimal solution less competitively due to this CS algorithm feature.

Based on this advantage, the CS algorithm is integrated into the GWO algorithm to obtain a better optimal solution for optimization problems. The GWO algorithm combined with cuckoo search was implemented by Xu, H., Liu, X., \& Su, J. in 2017 as the CS-GWO algorithm to solve the optimization problems [69]. In 2020, Abhishek Gupta proposed implementing a hybrid GWO-CS algorithm to test different benchmark optimization functions and found that the performance is better in finding the optimal solution than the GWO algorithm alone [70].

The flow chart of the CS-GWO algorithm is shown in Fig. 1 and the pseudo-code explanation of the hybrid CS-GWO algorithm is as follows:

4.3.1. The pseudo-code of the CS-GWO algorithm is presented as follows [69] 
Initialize the grey wolf population $X_{i}(i=1,2, \ldots, n)$

Initialize $a, A, C$ and $\rho_{a}$

Compute the fitness of each search agent in the pack using eq. 1

Set $\overrightarrow{X_{\alpha}}, \overrightarrow{X_{\beta}}$ and $\overrightarrow{X_{\delta}}$ according to the fitness

$t=0$ (iteration=0)

while ( $t \leq$ Max number of iterations)

for wolf (each search agent)

Update the position of the current search agent by equation 27

end for

update a, $A, C$

Run load flow analysis with constraints

Calculate the fitness function using equation 1

Update $\overrightarrow{X_{\alpha}}, \overrightarrow{X_{\beta}}$ and $\overrightarrow{X_{\delta}}$,

For $\overrightarrow{X_{\alpha}}, \overrightarrow{X_{\beta}}$ and $\overrightarrow{X_{\delta}}$

Update the position by cuckoo search algorithm using the Levy flight method [14] by equation 28.

If the random number $>P_{a}$

Random change wolf's position

Compute the fitness function and update it according to the fitness

End for

$t=t+1$

end while

return $\overrightarrow{X_{\alpha}}$ output value

4.3.2. Implementation of CS-GWO for DNR considering DGs installation:

Step 1: Initialization of problem and parameters of the algorithm

The optimization problem is specified as follows:

Subjected to $y_{i} \in Y_{i} i=1,2, \ldots N$

Minimize $f(y)$

Where $f(y)$ is an objective function; $y$ is the set of each decision variable $y_{i} ; Y_{i}$ is the set of the possible range of values for each decision variable (lower and upper bound values). The decision variable in this algorithm is considered as opened switches, DGs size and Buses number. The grey wolf and cuckoo search parameters are specified in this step. The dimension of search agent $=12$, Number of search agents $=200$ wolfs, Max. iteration $=100, P_{a}=0.25$ (probability of alien eggs discovery). The grey wolf-cuckoo search memory (GWCM) is a location where all the solution vectors are stored (opened switches, DGs location and size, power loss value). Here the grey wolf coefficient vectors $\vec{A}, \vec{C}$ will be updated based on the components $\vec{a}$ $\left(\vec{a}=\left[2-\left(2-\frac{(2 * \text { current iteration })}{\text { max.iteration }}\right)\right]\right)$ which is linearly reduced from 2 to 0 throughout the repetition process and $\overrightarrow{r_{1}}$ and $\overrightarrow{r_{2}}$ denotes the arbitrary vectors $[0,1]$.

\section{Step2: Initialize GWCM}

In this step, the GWCM is filled with as many randomly generated solution vectors as the grey wolf population size ( wolfs $=200)$.

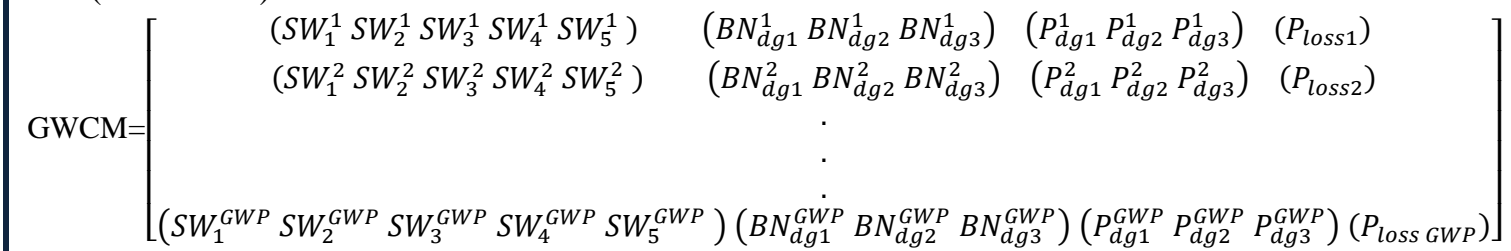

Where $\quad\left(S W_{1}^{1} S W_{2}^{1} S W_{3}^{1} S W_{4}^{1} S W_{5}^{1}\right) \quad$ indicates $\quad$ switches $\quad$ opened during reconfiguration, $\left(B N_{d g 1}^{1} B N_{d g 2}^{1} B N_{d g 3}^{1}\right)$ indicates the DGs installation at bus number, $\left(P_{d g 1}^{1} P_{d g 2}^{1} P_{d g 3}^{1}\right)$ indicates the size of the DGs and $P_{l o s s 1}$ total loss value obtained for that network reconfiguration. The matrix 
size of GWCM is $[200 \times 12]$ including randomly generated reconfiguration loops, DGs location and size depending on the number of switches in loops, limits of DGs size.

\section{Random generation of network reconfiguration topology considering DGs location and size}

$x=z \operatorname{eros}($ wolf, 12$)$;

$\% \% \%$ random generation of network configuration $\% \% \%$

$x(:, 1)=\operatorname{randi}(10,1$, wolf $) ; \%$ number switches in loop 1

$\ldots \ldots$

$x(:, 5)=\operatorname{randi}(8,1$, wolf $) ; \% 8$ is number switches in loop 5

$\% \%$ Random generation of DGs location at different buses \%\%

$x(:, 6)=\operatorname{randi}(33,1$, wolf $)$;

$\cdots$

$\% \%$ limits of DGs size power $\% \% \%$

$x(:, 9)=\operatorname{randi}(2000,1$, wolf $)$;

Step 3: Compute the fitness by using eq (1) of each search agent in the pack (each configuration randomly generated) using load flow analysis.

For $i=1$ : no. search agents

Calculate fitness value

End for

Set obtained $\overrightarrow{X_{\alpha}}, \overrightarrow{X_{\beta}}$ and $\overrightarrow{X_{\delta}}$ According to fitness.

Step 4: Initialize iter $=0$; Then $\vec{a}=0$ (for current iteration)

$\% \% \%$ main Loop $\% \% \%$

while (iter $\leq$ Max.iteration)

For each search agent (each network configuration, DGs location and size)

Update the position of the current search agent by eq. (27) (based on power loss value obtained)

End for

$\% \% \%$

Update $\vec{A}, \vec{C}$ and $\vec{a}$ using eq. (23 and 24)

Run load flow analysis with constraints

Compute the fitness value

Update $\overrightarrow{X_{\alpha}}, \overrightarrow{X_{\beta}}$ and $\overrightarrow{X_{\delta}}$ according to the fitness (where $\overrightarrow{X_{\alpha}}, \overrightarrow{X_{\beta}}$ and $\overrightarrow{X_{\delta}}$ are best three search agents related to the optimal solution obtained during the iteration process)

The matrix size of the $\overrightarrow{X_{\alpha}}$ is $[1 \times 11]$ include best network reconfiguration topology (switches to open), DGs location at bus number and size depending on minimum power loss.

Step 5: Incorporating a cuckoo search algorithm using the levy flight method to find the best configuration and DGs location and size.

For $\overrightarrow{X_{\alpha}}, \overrightarrow{X_{\beta}}$ and $\overrightarrow{X_{\delta}}$ obtained in step 4 are given as the input to the cuckoo search algorithm [14]

Levy flight method generates a new solution using eq. (28)

If rand $>P_{a}$

$\% \% \%$ controlling is sending back to GWO algorithm\%\%\%\%\%

Update $\vec{A}, \vec{C}$ in GWO algorithm according to the random best position obtained by cuckoo search algorithm (i.e., updating wolf position according to the obtained random values $\overrightarrow{r_{P 1}\left(X_{b e s t l}\right)}$ and $\overrightarrow{r_{P 2}\left(X_{b e s t l}\right)}$ from levy flight method)

Compute the fitness function and update it according to fitness

Compute the new position of a grey wolf using eq. (27)

Iteration $=$ iter +1

End while

Output alpha_score (displays the Open switches, DGs location at which bus number and DGs size)

The application of the hybrid CS-GWO algorithm for PL reduction problem and voltage profile improvement with DNR and DGs installation simultaneously is validated with the standard IEEE 33-bus test system. This test system comprises five tie switches, normally opened and represented as $33,34,35,36$, and 
37. Based on the number of tie switches, five loops have been formed as $L_{1}$ to $L_{5}$ as depicted in Fig. 2. Assume that DG units installed at buses as 18,22, and 25, as depicted in Fig. 2. DG size may change in discrete steps at the desired location during the optimization process. To obtain an optimal radial network topology, only open switches in the system need to be known.

The solution vector (SV) for DNR with DGs installation problem for all scenarios is represented from Equations (32)-(34).

$$
\begin{aligned}
& \mathrm{SV}=\{\underbrace{O S_{1}^{1}, O S_{2}^{1}, O S_{3}^{1}, O S_{4}^{1}, O S_{5}^{1}}_{\text {BASE AND RECONFIGURATION }} \rightarrow P_{\text {LOSS }}\} \\
& \mathrm{SV}=\{\underbrace{L O_{1}^{1}, L O_{2}^{1}, L O_{3}^{1}}_{\text {lOCATION OF DGS }}, \underbrace{S I_{1}^{1}, S I_{2}^{1}, S I_{3}^{1}}_{\text {SIZE OF } P+D G S}, \rightarrow P_{L O S S}\} \\
& \mathrm{SV}=\{\underbrace{O S_{1}^{1}, O S_{2}^{1}, O S_{3}^{1}, O S_{4}^{1}, O S_{5}^{1}}_{\text {RECONFIGURATION }}, \underbrace{L O_{1}^{1}, L O_{2}^{1}, L O_{3}^{1}}_{\text {lOCATION OF DGS }}, \underbrace{S I_{1}^{1}, S I_{2}^{1}, S I_{3}^{1}}_{\text {SIZE OF P+ DGS }}, \rightarrow P_{L O S S}\}
\end{aligned}
$$

where $O S_{1}^{1}, O S_{2}^{1}, O S_{3}^{1}, O S_{4}^{1}, O S_{5}^{1}$ are opened switches with respect to $(33,34,35,36,37)$ and $(69,70$, $71,72,73)$ tie switches. $L O_{1}^{1}, L O_{2}^{1}, L O_{3}^{1}$ are the locations of DG units. $S I_{1}^{1}, S I_{2}^{1}, S I_{3}^{1}$ and $S I_{4}^{1}, S I_{5}^{1}, S I_{6}^{1}$ are the sizes of DG units in MW and MVAR. For the base case analysis SV, Equation (32) is used to determine the optimal solution by choosing the best-reconfigured switches open in the loop. Equation (33) is used to solve scenarios III and IV, determining the optimum location and sizing of three DG units. Equation (34) is used to solve scenario V to perform simultaneous DNR with DGs installation to reduce PL and improve minimum system voltage magnitude.

In the proposed CS-GWO method, only three control parameters need to be adjusted, including the number of wolves, the maximum number of iterations and $P_{a}=0.25$ (probability of alien eggs discovery). The remaining parameters, such as switches to be opened in the loop, DG location at bus number, and DG size, are randomly selected. These parameters can easily be predetermined depending on the tested systems. The proposed method is executed independently for each scenario to obtain the optimal solution. The implemented algorithm has been coded in MATLAB R2017a software and simulated on a computer desktop with Intel Core (TM) i3 PC with $2.0 \mathrm{GHz}$ of speed and $8 \mathrm{~GB}$ of RAM.

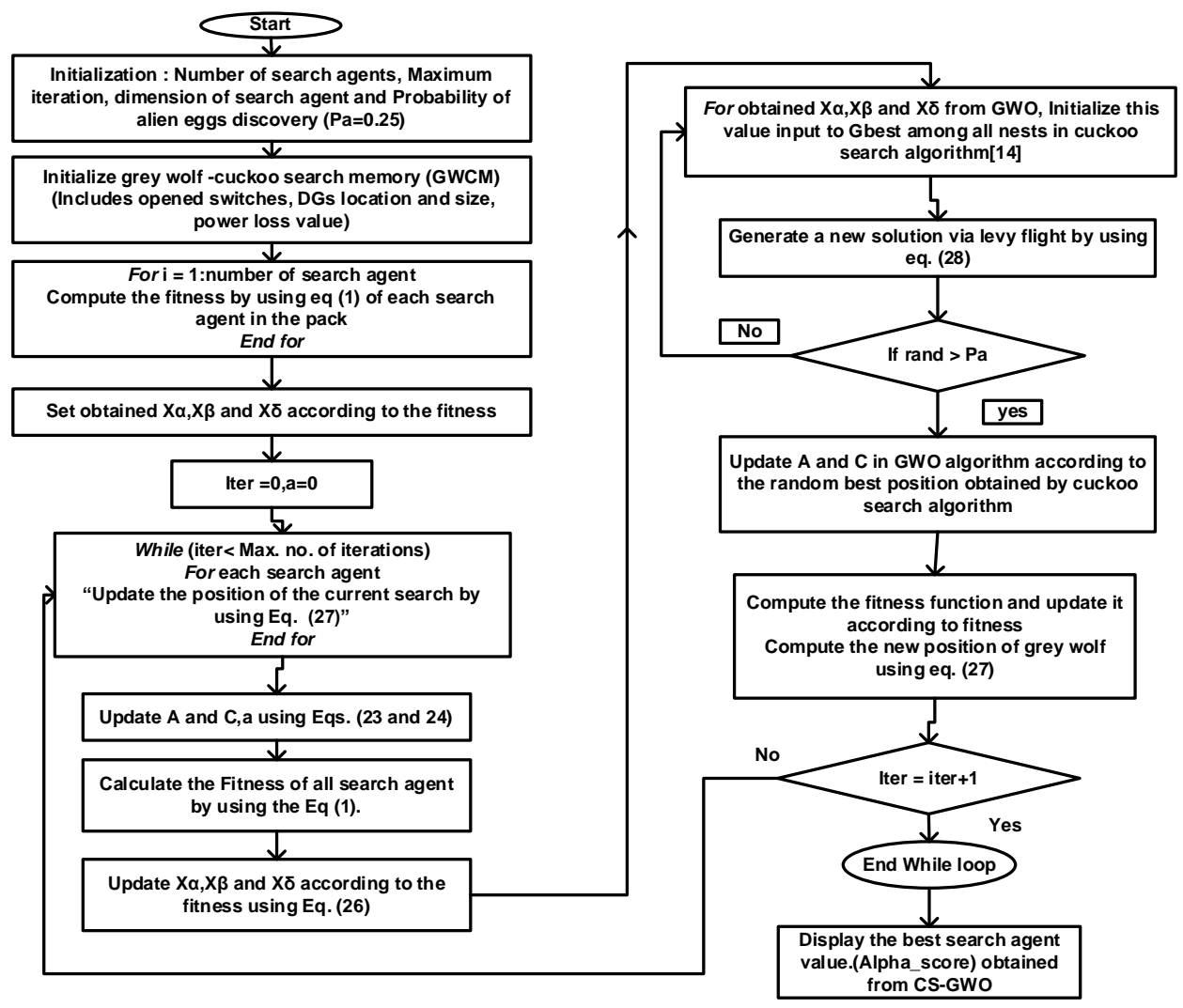

Figure 1. Flowchart of CS-GWO algorithm 


\section{TEST RESULTS}

The standard IEEE test systems 33-bus and 69-bus systems are considered for this work to show the proposed hybrid CS-GWO algorithm's effectiveness and robustness to solve the considered problem. Different type of scenarios was considered as follows:

- $\quad$ Scenario I: Base case (without DNR and DGs installation).

- Scenario II: DNR is done, depending on existing switches.

- $\quad$ Scenario III: DGs are installed in the DS before DNR (Only DG units).

- Scenario IV: DGs are installed after the DNR.

- Scenario V: Simultaneous DNR considering DGs installation.

\section{Test system-I: IEEE 33-bus system}

The topology of test system-I consists of 5 tie switches from 33-37, normally opened and 32 SS from 1-32 generally closed [71]. The system load data under the base case were $3715 \mathrm{~kW}$ and $2300 \mathrm{kVAR}$, respectively. The range of apparent power injected by the DGs is 0 to $2 \mathrm{MW} \& 2 \mathrm{MVAR}$, respectively. The base parameters are $100 \mathrm{MVA}, 12.66 \mathrm{kV}$. Table 1 shows the simulation results of test system 1 for different loading conditions and voltage deviation at load buses. Table 2 shows the CS-GWO algorithm's effectiveness compared with existing algorithms in obtaining optimal configuration, sizing, and location of DGs for all the scenarios considered and simulation results are presented. Fig. 2 depicts the single line diagram (SLD) of the considered test system 1 with different loop formation and DGs placement. Based on the number of tie switches, five loops have been formed as $L_{1}$ to $L_{5}$, these switches are operated during fault cases, load balance conditions and reduce system losses.

$\mathrm{L} 1=[2 ; 3 ; 4 ; 5 ; 6 ; 7 ; 33 ; 20 ; 19 ; 18] ; \mathrm{L} 2=[9 ; 10 ; 11 ; 12 ; 13 ; 14 ; 34] ; \mathrm{L} 3=[8 ; 9 ; 10 ; 11 ; 35 ; 21 ; 33]$ L4= [ $26 ; 27 ; 28 ; 29 ; 30 ; 31 ; 32 ; 36 ; 17 ; 16 ; 15 ; 34 ; 8 ; 7 ; 6] ; \mathrm{L} 5=[22 ; 23 ; 24 ; 37 ; 28 ; 27 ; 26 ; 25 ; 5 ; 4 ; 3]$

Table 1. Results of an IEEE 33-bus RDS using GWO and CS-GWO

\begin{tabular}{|c|c|c|c|c|c|}
\hline \multirow[t]{3}{*}{ Scenario } & \multirow[t]{3}{*}{ Item } & \multirow{3}{*}{$\begin{array}{c}\text { GWO } \\
\text { Nominal load } \\
(1.0)\end{array}$} & \multicolumn{3}{|c|}{ Proposed CS-GWO } \\
\hline & & & \multicolumn{3}{|c|}{ Load levels } \\
\hline & & & $\begin{array}{c}\text { Light load } \\
(0.5)\end{array}$ & $\begin{array}{c}\text { Nominal load } \\
(1.0)\end{array}$ & Heavy load (1.6) \\
\hline \multirow[t]{4}{*}{$\begin{array}{l}\text { Base case } \\
\text { (Scenario I) }\end{array}$} & $\begin{array}{l}\text { Open switch } \\
\text { numbers }\end{array}$ & $33,34,35,36,37$ & $33,34,35,36,37$ & $33,34,35,36,37$ & $33,34,35,36,37$ \\
\hline & $\begin{array}{l}\text { Power loss } \\
(\mathrm{kW})\end{array}$ & 202.68 & 47.072 & 202.68 & 575.39 \\
\hline & $\begin{array}{c}\text { Minimum } \\
\text { voltage (p.u.) }\end{array}$ & 0.9132 & 0.9582 & 0.9130 & 0.8528 \\
\hline & $\Delta V_{D}$ (p.u.) & 0.0868 & 0.0418 & 0.0870 & 0.1472 \\
\hline \multirow{6}{*}{$\begin{array}{c}\text { Only } \\
\text { reconfiguration } \\
\text { (Scenario II) }\end{array}$} & $\begin{array}{l}\text { Open switch } \\
\text { numbers }\end{array}$ & $7,9,14,32,37$ & $7,9,14,32,37$ & $7,9,14,32,37$ & $7,9,14,32,37$ \\
\hline & $\begin{array}{l}\text { Power loss } \\
\quad(\mathrm{kW})\end{array}$ & 139.55 & 33.269 & 139.55 & 380.45 \\
\hline & $\begin{array}{l}\text { Minimum } \\
\text { voltage (p.u.) }\end{array}$ & 0.9425 & 0.9698 & 0.9424 & 0.8640 \\
\hline & $\begin{array}{c}\text { Loss reduction } \\
(\%)\end{array}$ & 31.14 & 29.30 & 31.14 & 33.87 \\
\hline & $\Delta V_{D}$ (p.u.) & 0.0575 & 0.0302 & 0.0576 & 0.1360 \\
\hline & Iterations & 100 & 2 & 2 & 2 \\
\hline \multirow{4}{*}{$\begin{array}{c}\text { Only DG } \\
\text { Installation } \\
\text { (Scenario III) } \\
\text { (P Type) }\end{array}$} & $\begin{array}{l}\text { Opened } \\
\text { switches }\end{array}$ & $33,34,35,36,37$ & $33,34,35,36,37$ & $33,34,35,36,37$ & $33,34,35,36,37$ \\
\hline & $\begin{array}{l}\text { Size of DGs } \\
\text { (MW), } \\
\text { Bus number }\end{array}$ & $\begin{array}{l}0.7646(13) \\
1.2061(24) \\
1.1383(29)\end{array}$ & $\begin{array}{l}0.3750(14) \\
0.5435(24) \\
0.5247(30)\end{array}$ & $\begin{array}{c}0.7520(14) \\
1.096(24) \\
1.074(30)\end{array}$ & $\begin{array}{c}1.2152(14) \\
1.784(24) \\
1.7365(30)\end{array}$ \\
\hline & $\begin{array}{l}\text { Power loss } \\
\qquad(\mathrm{kW})\end{array}$ & 71.82 & 17.32 & 71.40 & 190.19 \\
\hline & $\begin{array}{l}\text { Minimum } \\
\text { voltage (p.u.) }\end{array}$ & 0.9785 & 0.9903 & 0.9804 & 0.9555 \\
\hline
\end{tabular}

IJEEI, Vol. 9, No. 4, December 2021: 880 - 906 


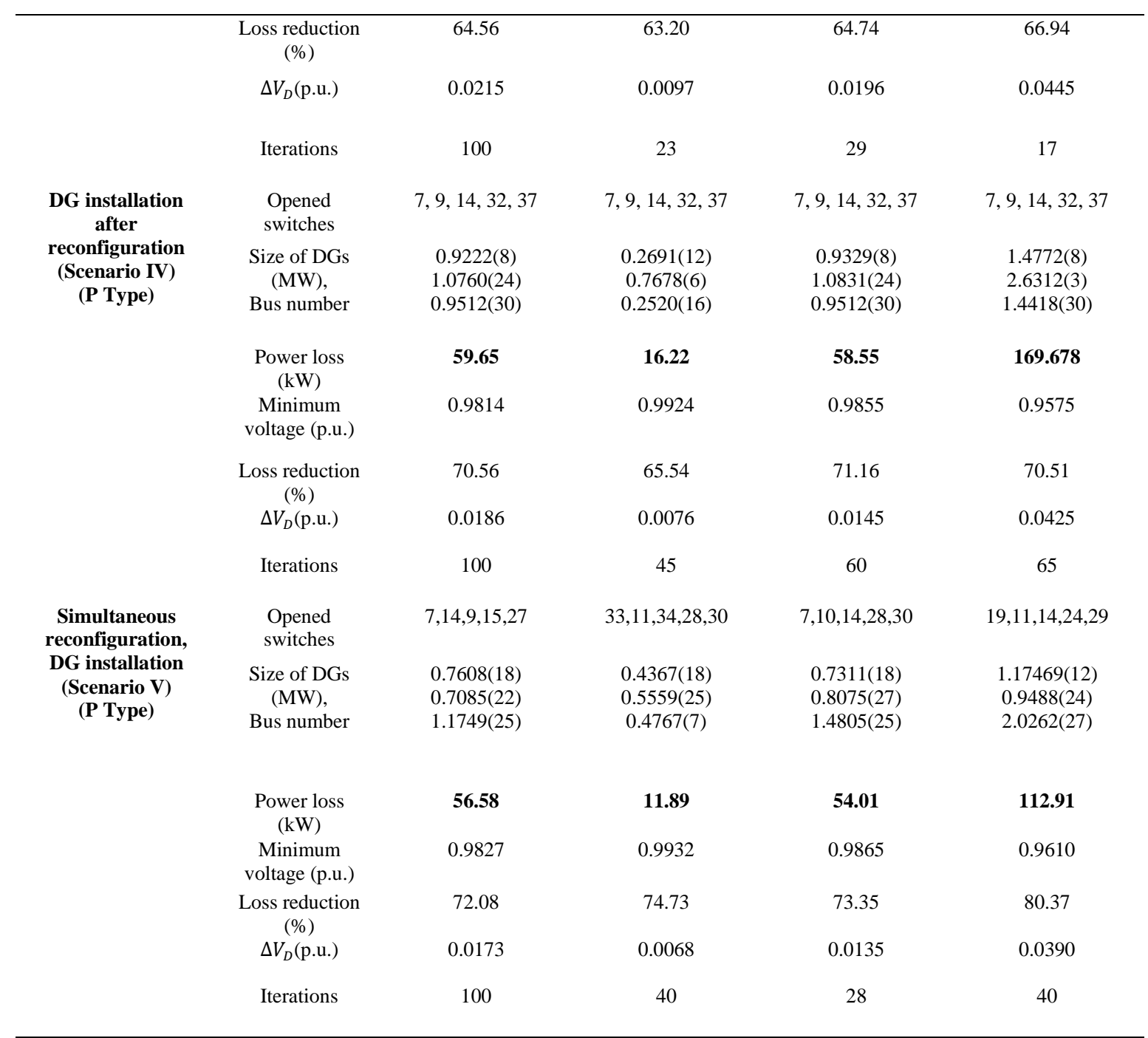

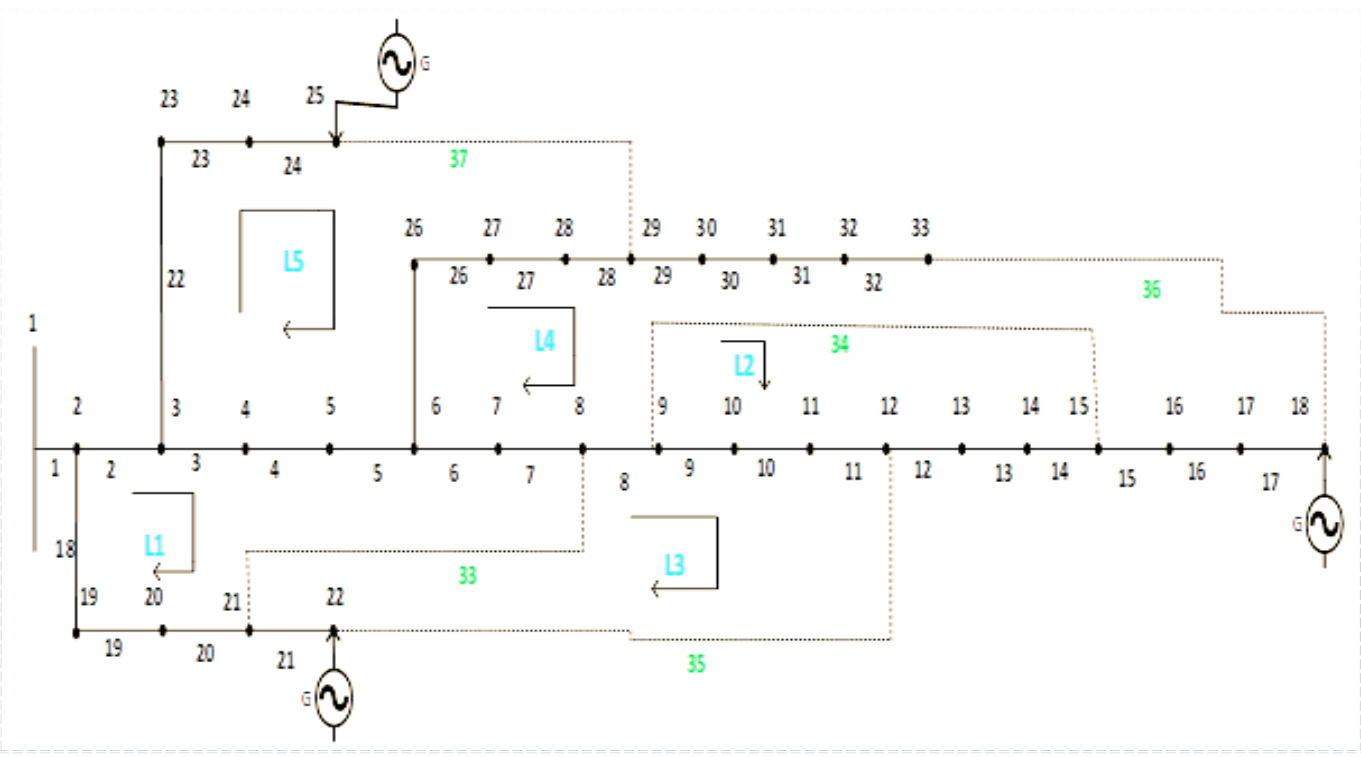

Figure 2. The IEEE 33-bus RDS, with different loops and DGs installation 
To estimate the performance of the hybrid CS-GWO algorithm, the network/system is simulated at three different load levels, such as light (0.5), nominal (1.0) and heavy (1.6); simulation results obtained are presented in Table 1. From Table 1, we can infer that at light load base case, PL in the system (in kW) is 47.07, which is drastically reduced to $33.26,17.32,16.22$, and 11.89 for scenarios II, III, IV and V, respectively. Similarly, at nominal load, base case PL (in $\mathrm{kW}$ ) is 202.68, which is reduced to $139.55,71.40,58.55$, and 54.01 for scenarios II, III, IV, and V, respectively. At heavy load, base case PL (in $\mathrm{kW}$ ) is 575.39, which is reduced to $380.45,190.19,169.67$, and 112.91 for scenarios II, III, IV, and V, respectively. The percentage PL reduction for scenario II to V at light load is $29.30,63.20,65.54$, and 73.35, respectively. Similarly, at nominal and heavy load conditions is $31.14,64.74,71.16,74.50$ and $33.87,66.94,70.51,80.37$ respectively. These obtained results show that PL minimization using scenario-V by the proposed hybrid CS-GWO technique is maximized for all load levels, proving the proposed method's effectiveness over the other algorithms. It is observed from results that as load rises from light to heavy, enhancement in percentage PL reduction in all scenarios is nearly the same. It is pertinent from Table 1 that PL reduction and voltage profile improvement for scenario $\mathrm{V}$ are higher when compared to scenario IV. This Table also provides the estimated PL value (in $\mathrm{kW}$ ) and $\Delta V_{D}$ (p.u.) as $\{202.68,139.55,71.82,59.65,56.58\}$ and $\{0.0868,0.0575,0.0215,0.0186,0.0173\}$ using the GWO algorithm. From this Table, the results obtained from the hybrid CS-GWO algorithm are better than the GWO algorithm.

Furthermore, the system voltage profile (in p.u.) is being improved from 0.9582 to 0.9932 in light load condition and similarly 0.9130 to 0.9865 in nominal load; 0.8528 to 0.9610 in heavy load condition. The percentage minimum voltage improvement for scenarios II to $\mathrm{V}$ at the light, medium and heavy load estimated from the proposed method are 1.19,3.24,3.44,3.52; 3.11,6.87,7.35,7.45 and 1.29,10.74,10.93,11.25, respectively. From this, it is noted that the voltage profile and percentage minimum voltage improvement of the DS for scenario V is higher than in other scenarios. Incidentally, the voltage deviation (in p.u) estimated for light, nominal and heavy load for scenario I-V using CS-GWO method are 0.0418,0.0302,0.0097,0.0076,0.0068; $\quad 0.0870,0.0576,0.0196,0.0145,0.0135 \quad$ and $0.1472,0.1360,0.0445,0.0425,0.0390$, respectively.

Table 2. Comparison of results with other algorithms for the IEEE 33-bus system

\begin{tabular}{|c|c|c|c|c|c|c|c|c|c|c|}
\hline Scenario & Item & $\begin{array}{c}\text { FWA } \\
{[43]}\end{array}$ & $\begin{array}{c}\text { RGA } \\
{[5]}\end{array}$ & $\begin{array}{c}\text { GA } \\
{[15]}\end{array}$ & $\begin{array}{c}\text { HSA } \\
{[6]}\end{array}$ & $\begin{array}{c}\text { ACS } \\
\mathbf{A} \\
{[14]}\end{array}$ & $\begin{array}{c}\text { UVD } \\
\text { A } \\
{[48]}\end{array}$ & $\begin{array}{c}\text { MPGS } \\
\text { A } \\
{[44]}\end{array}$ & $\begin{array}{l}\text { SFS } \\
{[58]}\end{array}$ & $\begin{array}{l}\text { Proposed } \\
\text { CS-GWO }\end{array}$ \\
\hline \multirow[t]{3}{*}{$\begin{array}{c}\text { Base case } \\
(\text { Scenario I) }\end{array}$} & $\begin{array}{l}\text { Opened } \\
\text { switches }\end{array}$ & \begin{tabular}{|c|}
33, \\
34, \\
35, \\
36,37
\end{tabular} & $\begin{array}{c}33,34 \\
35,36 \\
37\end{array}$ & $\begin{array}{c}33,34 \\
35,36 \\
37\end{array}$ & $\begin{array}{c}33,34 \\
35,36 \\
37\end{array}$ & $\begin{array}{c}33, \\
34, \\
35, \\
36,37\end{array}$ & $\begin{array}{c}33,34, \\
35,36 \\
37\end{array}$ & $\begin{array}{c}33,34 \\
35,36 \\
37\end{array}$ & $\begin{array}{c}33 \\
34, \\
35, \\
36,37\end{array}$ & $\begin{array}{c}33,34,35, \\
36,37\end{array}$ \\
\hline & $\begin{array}{c}\text { Power } \\
\text { loss }(\mathrm{kW})\end{array}$ & $\begin{array}{c}202.6 \\
8\end{array}$ & 202.68 & 202.68 & 202.68 & $\begin{array}{c}202.6 \\
8\end{array}$ & 202.68 & 202.68 & $\begin{array}{c}202.6 \\
8\end{array}$ & 202.68 \\
\hline & $\begin{array}{l}\text { Minimu } \\
\text { m } \\
\text { voltage } \\
\text { (p.u.) }\end{array}$ & $\begin{array}{c}0.913 \\
1\end{array}$ & 0.9131 & 0.9131 & 0.9131 & $\begin{array}{c}0.913 \\
1\end{array}$ & 0.9131 & 0.9131 & $\begin{array}{c}0.913 \\
1\end{array}$ & 0.9130 \\
\hline \multirow[t]{3}{*}{$\begin{array}{c}\text { Only } \\
\text { reconfiguration } \\
\text { (Scenario II) }\end{array}$} & $\begin{array}{l}\text { Opened } \\
\text { switches }\end{array}$ & $\begin{array}{c}7,9 \\
14, \\
28,32\end{array}$ & $\begin{array}{c}07,09 \\
14,32 \\
37\end{array}$ & $\begin{array}{c}33,34,9 \\
36,28\end{array}$ & $\begin{array}{l}7,10, \\
14, \\
32,28\end{array}$ & $\begin{array}{c}7,9 \\
14, \\
28,32\end{array}$ & $\begin{array}{c}7,9, \\
14, \\
32,37\end{array}$ & $\begin{array}{c}7,9,14 \\
32,37\end{array}$ & $\begin{array}{c}7,9 \\
14, \\
32,37\end{array}$ & $\begin{array}{c}7,9,14 \\
32,37\end{array}$ \\
\hline & $\begin{array}{l}\text { Minimu } \\
\text { m } \\
\text { voltage } \\
\text { (p.u.) }\end{array}$ & $\begin{array}{c}0.941 \\
3\end{array}$ & 0.9315 & 0.9310 & 0.9336 & $\begin{array}{c}0.941 \\
0\end{array}$ & 0.9378 & 0.9343 & $\begin{array}{c}0.937 \\
8\end{array}$ & 0.9424 \\
\hline & $\begin{array}{l}\text { Loss } \\
\text { reduction } \\
(\%)\end{array}$ & 30.93 & 30.93 & 30.13 & 27.77 & 30.93 & 31.15 & 31.16 & 31.15 & 31.14 \\
\hline \multirow[t]{2}{*}{$\begin{array}{c}\text { Only DG } \\
\text { Installation } \\
\text { (Scenario III) }\end{array}$} & $\begin{array}{l}\text { Opened } \\
\text { switches }\end{array}$ & $\begin{array}{c}33, \\
34, \\
35, \\
36,37\end{array}$ & $\begin{array}{c}33,34 \\
35,36 \\
37\end{array}$ & $\begin{array}{c}33,34 \\
35,36 \\
37\end{array}$ & $\begin{array}{c}33,34 \\
35,36 \\
37\end{array}$ & $\begin{array}{c}33 \\
34, \\
35, \\
36,37\end{array}$ & $\begin{array}{c}33,34 \\
35,36 \\
37\end{array}$ & $\begin{array}{c}33,34 \\
35,36 \\
37\end{array}$ & $\begin{array}{c}33 \\
34 \\
35, \\
36,37\end{array}$ & $\begin{array}{c}33,34,35 \\
36,37\end{array}$ \\
\hline & $\begin{array}{c}\text { Size of } \\
\text { DGs } \\
\text { (MW), } \\
\text { Bus } \\
\text { number }\end{array}$ & $\begin{array}{c}0.589 \\
7 \\
(14) \\
0.189 \\
5 \\
(18) \\
1.014 \\
6 \\
(32)\end{array}$ & 1.777 & 1.6044 & $\begin{array}{c}0.1070 \\
(18) \\
0.5724 \\
(17) \\
1.0462 \\
(33)\end{array}$ & $\begin{array}{c}0.779 \\
8 \\
(14) \\
1.251 \\
(24) \\
1.349 \\
6 \\
(30)\end{array}$ & $\begin{array}{c}0.875 \\
(11) \\
0.931 \\
(24) \\
0.925 \\
(29)\end{array}$ & $\begin{array}{c}0.1058 \\
(17) \\
0.5900 \\
(18) \\
1.0812 \\
(33)\end{array}$ & $\begin{array}{c}0.754 \\
0 \\
(14) \\
1.099 \\
4 \\
(24) \\
1.071 \\
4 \\
(30)\end{array}$ & $\begin{array}{c}0.7520 \\
(14) \\
1.096 \\
(24) \\
1.074 \\
(30)\end{array}$ \\
\hline
\end{tabular}




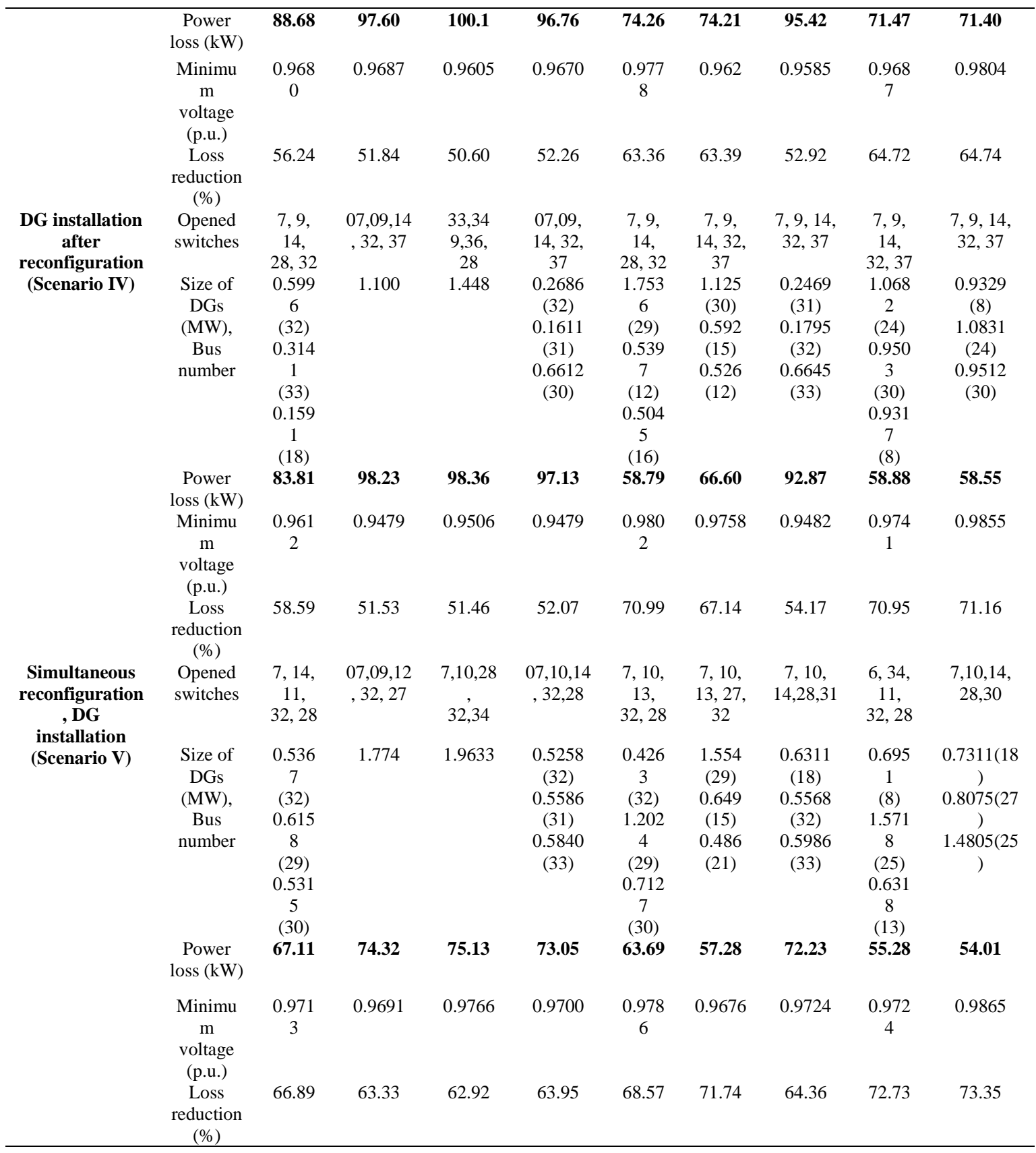

From the obtained results, the DNR with DG installation minimizes voltage deviation closer to zero, improving voltage stability and network performance. The optimal network structure after simultaneous DNR, considering the DGs installation for scenario V, is 8,12,15,29,31 with DGs size (MW) 0.8075,0.7311,1.4805 located at buses $27,18,25$ having PL of $51.01 \mathrm{~kW}$ respectively. The voltage profile curve for scenario I-V under nominal load is shown in Fig. 3. From this Figure, it is observed that the voltage profile for scenario $\mathrm{V}$ is better compared to other scenarios. The minimum voltage magnitude (in p.u) of DS is 0.9130 , which is enhanced to $0.9424,0.9804,0.9855$ and 0.9865 using scenarios I-V.

Table 2 represents the comparison of results obtained by hybrid CS-GWO with different algorithms such as RGA [5], HSA [6], ACSA [14], GA [15], FWA [43], MPGSA [44], UVDA [48] and SFA [58].

- For scenario II, hybrid CS-GWO optimized NR with opened switches: 7-9-14-32-37, estimated PL and minimum voltage magnitude as $139.55 \mathrm{~kW}$ and $0.9424 \mathrm{p} . \mathrm{u}$, the obtained results do not vary when compared to other methods.

- For scenario III (DGs installation only) obtained optimal location and sizing (MW) of DGs at buses $\{14,24,30\}$ and $\{0.7520,1.096,1.074\}$ respectively. The proposed method provided the minimum PL and improved voltage profile compared with other methods. 
- For scenario IV, the proposed method estimates the optimal DGs sizes (MW) of $\{0.9329,1.083$ and $0.9512\}$ for the installation at buses $\{8,24,30\}$. It is estimated that the PL obtained by the proposed method is minimal compared to other methods, i.e., $58.55 \mathrm{~kW}$ and improved voltage magnitude of 0.985 p.u.

- For scenario V, the proposed method provides optimal DNR along with DGs installation with opened switches: $8,12,15,29,31$, the optimal DGs installation at buses $\{27,18,25\}$ with sizes (MW) of $\{0.8075,0.7311,1.4805\}$. It is estimated that the power loss obtained in this scenario by the proposed hybris CS-GWO algorithm is minimal compared to other methods, i.e., $54.01 \mathrm{~kW}$ and improved voltage magnitude of 0.9865 p.u.

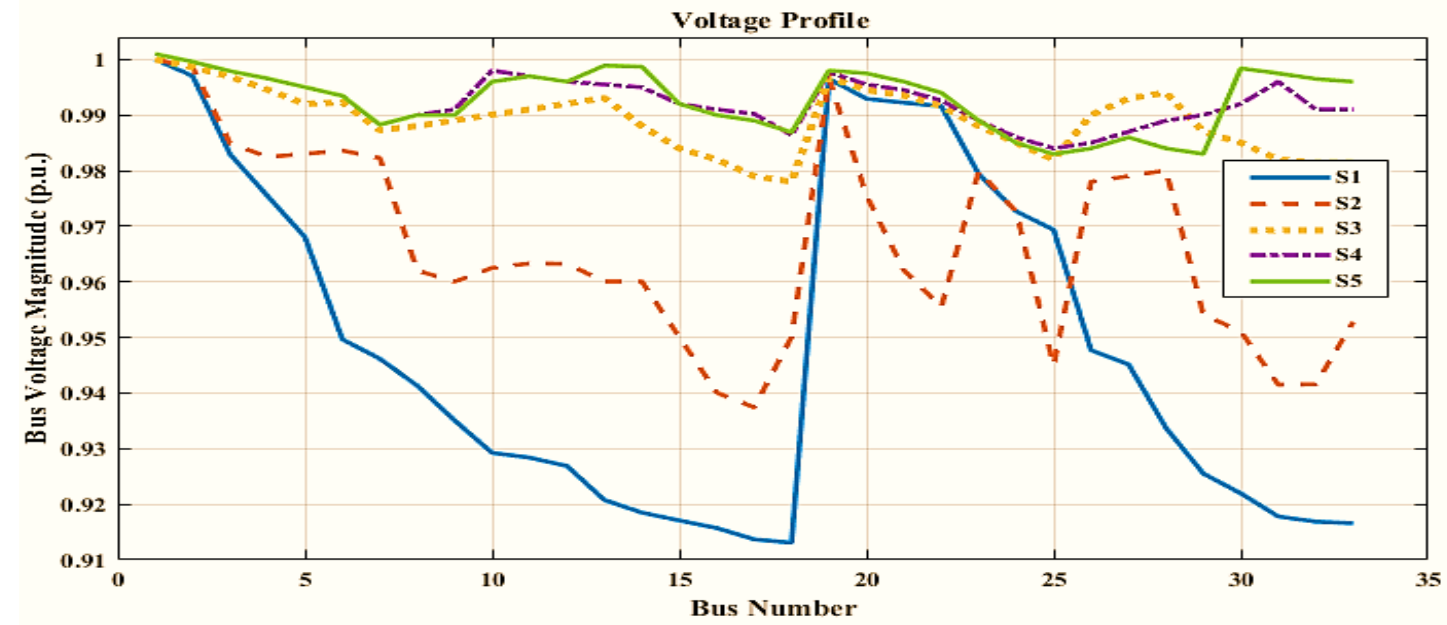

Figure 3. Voltage profile curves of an IEEE 33-bus system using hybrid CS-GWO algorithm

Convergence characteristics are also estimated for two scenarios II and V by considering the IEEE 33-bus system and depicted in Fig. 4a and 4b, respectively. In Fig. 4a, it is observed that, from the $1^{\text {st }}$ iteration onwards, PL decreased from $140.77 \mathrm{~kW}$ to $139.55 \mathrm{~kW}$ for scenario II. From Fig. $4 \mathrm{~b}$ at $30^{\text {th }}$ iteration onwards, PL decreased from $60.00 \mathrm{~kW}$ to $54.01 \mathrm{~kW}$ for scenario V. From Fig. 4a, it is pertinent to note that the proposed hybrid CS-GWO technique has converged to an optimal solution after $2^{\text {nd }}$ iteration for scenario II, showing that by integrating cuckoo search in GWO algorithm may find a better solution within less computation time of convergence process. Similarly, from Fig. $4 \mathrm{~b}$, it is found that the algorithm converges at the $28^{\text {th }}$ iteration providing an optimal solution with minimum power loss in scenario $\mathrm{V}$ compared to other algorithms found in the exhaustive literature survey.

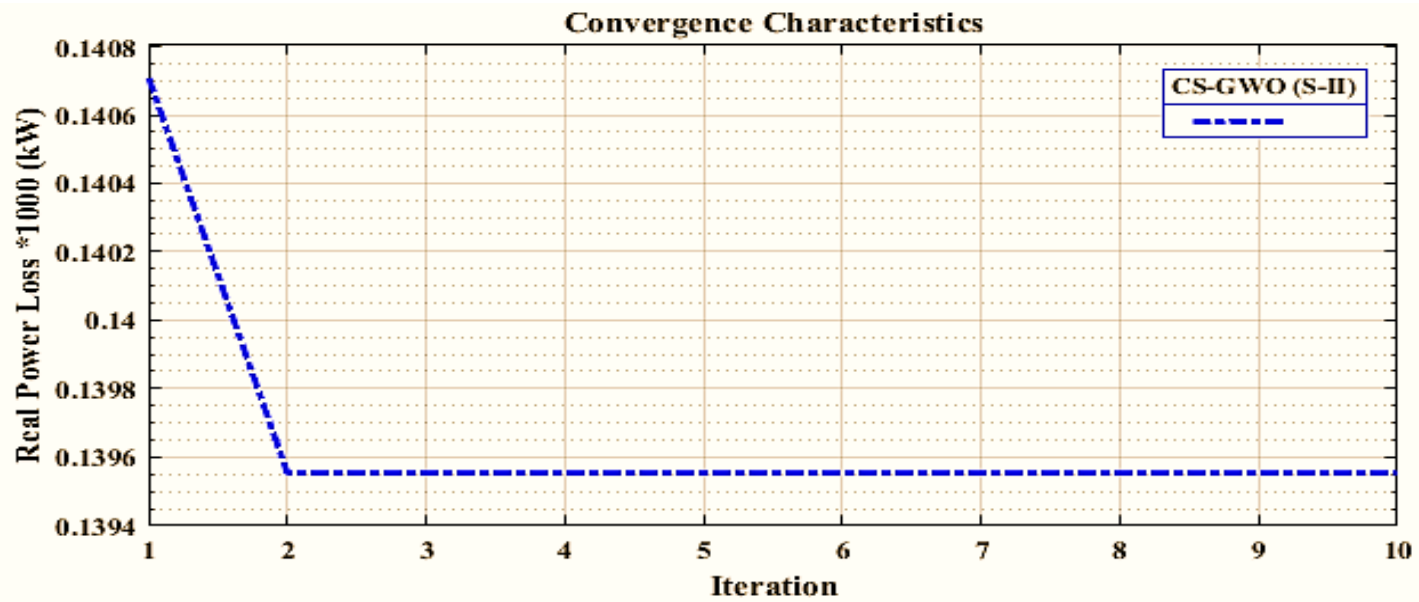

Figure 4a. Convergence characteristics for scenario II of IEEE 33-bus system using hybrid CS-GWO algorithm. 


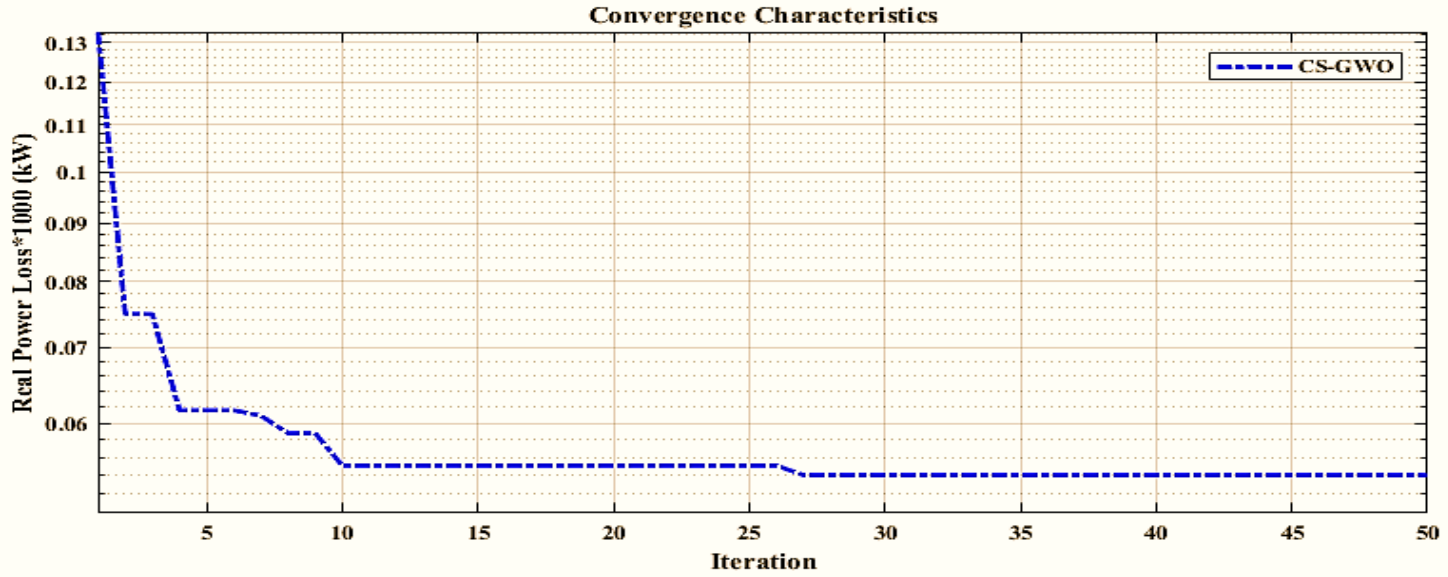

Figure 4b. Convergence characteristics for scenario V of IEEE 33-bus system using CS-GWO algorithm.

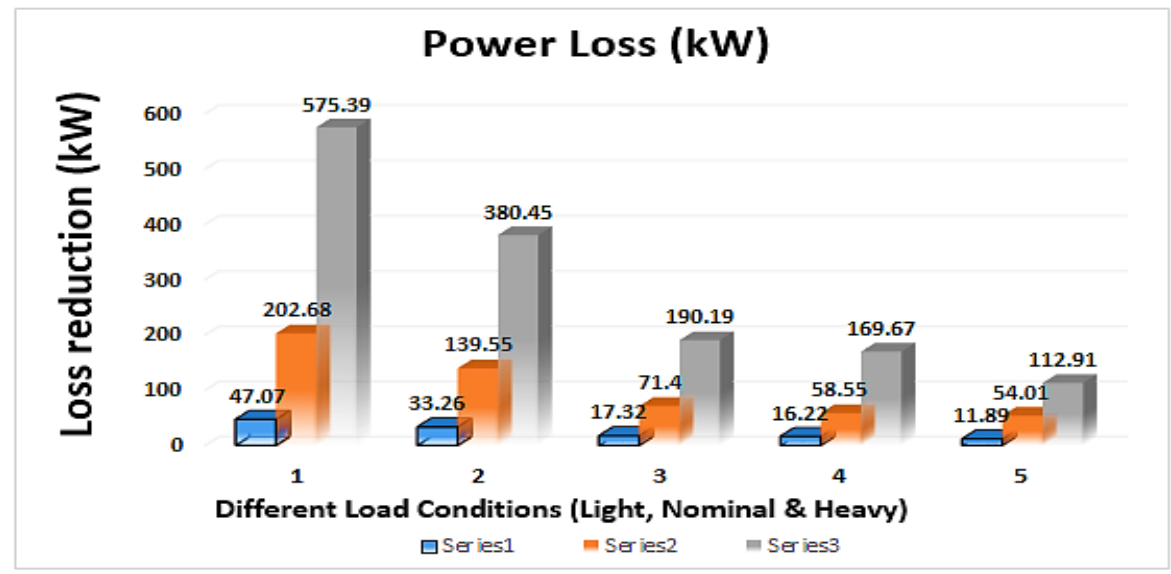

Figure 5. Power loss of an IEEE 33-bus system using hybrid CS-GWO algorithm under different loading conditions

The reduction in active PL obtained in the base case and to those obtained from different scenarios for light, nominal and heavy load conditions is represented as a bar graph in Fig. 5, From which the active PL (in $\mathrm{kW}$ ) in the base case for nominal load is 202.68, and it is reduced drastically to $139.55,71.40,58.55,51.98$ for scenarios II, III, IV, V respectively. From Table 2, it is concluded that the PL reduction obtained by the proposed hybrid technique is higher than the results obtained with GA, UVDA, MPGSA, SFS, and FWA methods. From these results, the percentage PL reduction by the proposed hybrid CS-GWO method for scenarios II, III, IV, and V were $31.14 \%, 64.74 \%, 71.16 \%$, and $74.50 \%$, respectively. Whereas with MPGSA, UVDA and SFS, it is $\{31.16 \%, 63.39 \%, 67.14 \%$, and $71.74 \%\} ;\{31.15 \%, 52.92 \%, 54.17 \%$, and $64.36 \%\}$; and $\{31.15 \%, 64.72 \%, 70.95 \%$, and $72.50 \%\}$ respectively. Hence the performance in terms of active PL minimization and voltage profile improvement, the proposed hybrid CS-GWO algorithm proved better performance for obtaining optimal solution when compared to the other optimization techniques.

\section{Test system-II: IEEE 69-bus system}

The topology of the test system consists of 68 SS (1-68) and 5 tie switches from (69-73) and system data were considered from [72]. The total load data under the base case were 3.80 MW and 2.694 kVAR, respectively. Table 3 shows the simulation results of test system 2 with installed DGs for different loading conditions and also computed voltage deviation $\Delta V_{D}$ (p.u.) at load buses. Table 4 shows the effectiveness of the hybrid CS-GWO algorithm compared with existing algorithms in obtaining optimal configuration, sizing and location of DGs for all the scenarios considered and simulation results are presented. Fig. 6 depicts the SLD of test system 2 with different loops and DGs placement. Depending on the number of tie switches, five loops have been formed as $L_{1}$ to $L_{5}$, these switches are operated during fault cases, load balancing conditions and to reduce the system losses.

$\mathrm{L} 1=[3,4,5,6,7,8,9,36,37,38,39,40,41,42,35] ; \mathrm{L} 2=[11,12,13,14,44,43,45] ; \mathrm{L} 3=[15,16,17,18,19,20] ;$

$\mathrm{L} 4=[21,22,23,24,25,26,59,60,61,62,63,64] ; \mathrm{L} 5=[47,48,49,53,54,55,56,57,52,46,58]$ 
To evaluate the effectiveness of proposed method, test system 2 is also simulated at different load levels such as light (0.5), nominal (1.0), and heavy (1.6), and obtained results are conferred in Table 3. From Table 3, we can infer that base case PL in the DS (in $\mathrm{kW}$ ) at light load is 51.60, which is reduced to 23.43, $18.14,11.54$ and 9.545 using scenarios II, III, IV, and V, respectively. Similarly, at nominal load, base case PL in the system (in $\mathrm{kW}$ ) is 224.70, which is reduced to 98.12,70.98,36.07 and 34.28 using scenarios II, III, IV, and V, respectively. Base case PL in the DS (in $\mathrm{kW}$ ) at heavy load is 652.45, which is reduced to 271.16, 186.30, 96.42, and 72.65 using scenarios II, III, IV, and V, respectively. The percentage loss reduction for scenarios II to $\mathrm{V}$ at light load is $54.59,64.84,77.63$ and 81.50 , respectively. Similarly, the percentage loss reduction for scenarios II to $\mathrm{V}$ at nominal and heavy load conditions is $\{56.33,68.39,83.94,84.74\}$; and $\{58.43,71.44,85.22,88.86\}$ respectively.

This represents that for all load levels, PL reduction using scenario-V by the proposed hybrid CSGWO algorithm is highest, proving the proposed method's effectiveness over the GWO method. As load level rises from light to heavy, enhancement in percentage PL reduction in all scenarios is nearly the same. It is pertinent from table 3 that reduction in PL and voltage profile improvement for scenario $\mathrm{V}$ is higher in comparison with scenario IV. As well as, this Table also provides the estimated PL value (in $\mathrm{kW}$ ) and $\Delta V_{D}$ (p.u.) as $\{225.00,98.53,71.65,37.07,40.28\}$ and $\{0.0908,0.0508,0.0220,0.0178,0.0193\}$ using the GWO algorithm. From this Table, the results obtained from the hybrid CS-GWO algorithm are better than the GWO algorithm.

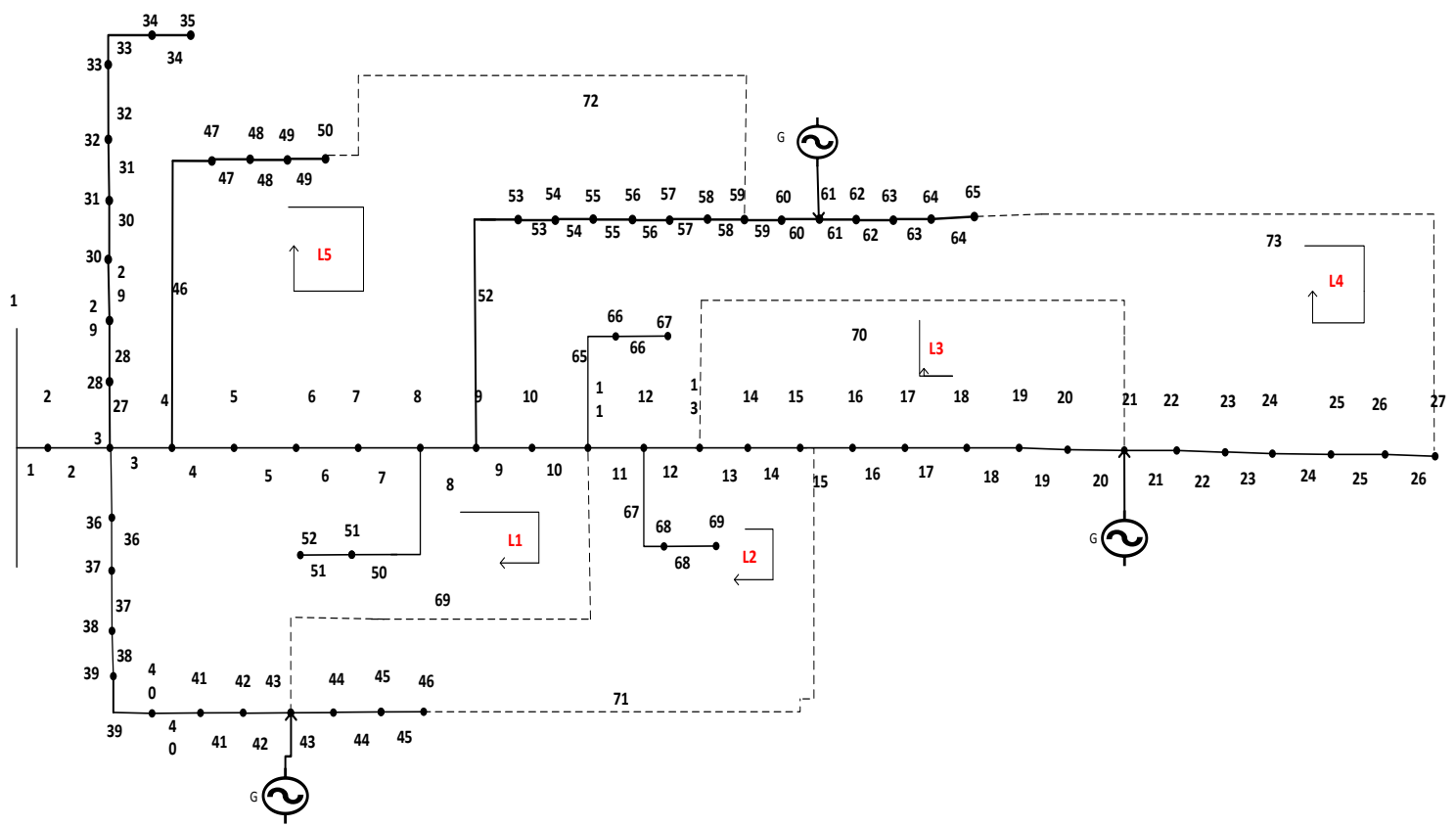

Figure 6. SLD of IEEE 69-bus RDS, with different loops and DGs placement

Furthermore, that the voltage profile (in p.u.) of the DS was improved from 0.9561 to 0.9875 in light load condition. Similarly, from 0.9094 to 0.9842 in nominal load; 0.8544 to 0.9625 in heavy load condition, respectively. The percentage minimum voltage improvement of the system for scenario II to $\mathrm{V}$ at light, medium and heavy load estimated from proposed method is $\{1.70,3.11,2.85,3.17\} ;\{4.22,7.05,7.52,7.60\}$ and $\{5.72,10.71,10.44,11.23\}$, respectively. From this, it is noted that voltage profile and percentage minimum voltage improvement of the DS for scenario $\mathrm{V}$ is the highest in comparison with other scenarios. Incidentally, the voltage deviation (in p.u) estimated for light, nominal and heavy load for scenario I-V using hybrid CSGWO method is $\{0.0439,0.0273,0.0132,0.0158,0.0125\} ;\{0.0906,0.0505,0.0216,0.0166,0.0158\}$ and $\{0.1456,0.0937,0.0431,0.0459,0.0375\}$, respectively.

From the obtained results, the DNR with DG installation minimizes voltage deviation closer to zero, which will improve voltage stability and network performance. After simultaneous DNR, considering the DGs installation for scenario $\mathrm{V}$, the network's optimal structure is $13,56,69,24,18$ with DGs size (MW) as $0.3738,0.3888,1.6764$ located at buses $24,32,61$ having power losses of $34.28 \mathrm{~kW}$ and minimum voltage magnitude of $0.9842 \mathrm{p} . \mathrm{u}$ respectively. The voltage profile curve for scenario I-V under nominal load is depicted in Fig. 7. From this Figure, it is observed that the voltage profile for scenario V is better compared to other scenarios. For example, the minimum voltage magnitude (in p.u) of the DS is 0.9094 , which is later enhanced to $0.9495,0.9784,0.9834$ and 0.9842 using scenarios I-V. 
Table 3. Results of an IEEE 69-bus RDS using GWO and hybrid CS-GWO

\begin{tabular}{|c|c|c|c|c|c|}
\hline \multirow[t]{2}{*}{ Scenario } & \multirow[t]{2}{*}{ Item } & \multirow{2}{*}{$\begin{array}{c}\text { GWO } \\
\text { Nominal load } \\
(1.0)\end{array}$} & \multicolumn{3}{|c|}{ Proposed CS-GWO } \\
\hline & & & $\begin{array}{c}\text { Light load } \\
(0.5)\end{array}$ & Nominal load (1.0) & Heavy load (1.6) \\
\hline \multirow{4}{*}{$\begin{array}{c}\text { Base case } \\
(\text { Scenario I) }\end{array}$} & Opened switches & $69,70,71,72,73$ & $69,70,71,72,73$ & $69,70,71,72,73$ & $69,70,71,72,73$ \\
\hline & Power loss (kW) & 225.00 & 51.60 & 224.70 & 652.45 \\
\hline & $\begin{array}{l}\text { Minimum voltage } \\
\text { (p.u.) }\end{array}$ & 0.9092 & 0.9561 & 0.9094 & 0.8544 \\
\hline & $\Delta V_{D}$ (p.u.) & 0.0908 & 0.0439 & 0.0906 & 0.1456 \\
\hline \multirow{6}{*}{$\begin{array}{c}\text { Only } \\
\text { reconfiguration } \\
\text { (Scenario II) }\end{array}$} & Opened switches & $69,71,14,55,61$ & $69,20,12,55,61$ & $69,20,12,56,61$ & $69,20,12,58,61$ \\
\hline & Power loss (kW) & 98.53 & 23.43 & 98.12 & 271.16 \\
\hline & $\begin{array}{l}\text { Minimum voltage } \\
\text { (p.u.) }\end{array}$ & 0.9492 & 0.9727 & 0.9495 & 0.9063 \\
\hline & Loss reduction (\%) & 56.19 & 54.59 & 56.33 & 58.43 \\
\hline & $\Delta V_{D}$ (p.u.) & 0.0508 & 0.0273 & 0.0505 & 0.0937 \\
\hline & Iterations & 60 & 4 & 3 & 7 \\
\hline \multirow{6}{*}{$\begin{array}{c}\text { Only DG } \\
\text { Installation } \\
\text { (Scenario III) } \\
\text { (P Type) }\end{array}$} & Opened switches & $69,70,71,72,73$ & $69,70,71,72,73$ & $69,70,71,72,73$ & $69,70,71,72,73$ \\
\hline & $\begin{array}{l}\text { Size of DG in MW } \\
\text { (Bus number) } \\
\text { Power loss (kW) }\end{array}$ & $\begin{array}{c}0.5147(17) \\
1.7798(61) \\
1.4710(47) \\
\mathbf{7 1 . 6 5}\end{array}$ & $\begin{array}{c}0.2618(18) \\
1.4373(4) \\
0.8752(61) \\
\mathbf{1 8 . 1 4}\end{array}$ & $\begin{array}{c}0.5202(18) \\
0.7509(50) \\
1.7644(61) \\
\mathbf{7 0 . 9 8}\end{array}$ & $\begin{array}{c}0.8531(18) \\
1.2536(49) \\
1.9008(61) \\
\mathbf{1 8 6 . 3 0}\end{array}$ \\
\hline & $\begin{array}{l}\text { Minimum voltage } \\
\text { (p.u.) }\end{array}$ & 0.9780 & 0.9868 & 0.9784 & 0.9569 \\
\hline & Loss reduction (\%) & 68.15 & 64.84 & 68.39 & 71.44 \\
\hline & $\Delta V_{D}$ (p.u.) & 0.0220 & 0.0132 & 0.0216 & 0.0431 \\
\hline & Iterations & 65 & 14 & 32 & 34 \\
\hline \multirow{6}{*}{$\begin{array}{l}\text { DG installation } \\
\text { after } \\
\text { reconfiguration } \\
\text { (Scenario IV) } \\
\text { (P Type) }\end{array}$} & Opened switches & $69,14,70,61,57$ & $69,14,70,61,57$ & $69,14,70,61,57$ & $69,13,70,61,56$ \\
\hline & $\begin{array}{l}\text { Size of DG in MW } \\
\text { (Bus number) } \\
\text { Power loss (kW) }\end{array}$ & $\begin{array}{c}0.6940(67) \\
0.5333(25) \\
1.3008(61) \\
\mathbf{3 7 . 0 7}\end{array}$ & $\begin{array}{c}0.1945(60) \\
0.1142(58) \\
0.4584(61) \\
\mathbf{1 1 . 5 4}\end{array}$ & $\begin{array}{c}0.6950(64) \\
0.5401(12) \\
1.2008(61) \\
\mathbf{3 6 . 0 7}\end{array}$ & $\begin{array}{c}0.3315(60) \\
1.1551(57) \\
1.9586(61) \\
\mathbf{9 6 . 4 2}\end{array}$ \\
\hline & $\begin{array}{l}\text { Minimum voltage } \\
\text { (p.u.) }\end{array}$ & 0.9822 & 0.9842 & 0.9834 & 0.9541 \\
\hline & Loss reduction (\%) & 83.52 & 77.63 & 83.94 & 85.22 \\
\hline & $\Delta V_{D}$ (p.u.) & 0.0178 & 0.0158 & 0.0166 & 0.0459 \\
\hline & Iterations & 80 & 40 & 45 & 50 \\
\hline \multirow{7}{*}{$\begin{array}{l}\text { Simultaneous } \\
\text { reconfiguration, } \\
\text { DG installation } \\
\text { (Scenario V) } \\
\text { (P Type) }\end{array}$} & Opened switches & $10,14,15,63,57$ & $69,20,71,57,26$ & $13,56,69,24,18$ & $69,70,13,57,63$ \\
\hline & $\begin{array}{l}\text { Size of DG in MW } \\
\text { (Bus number) }\end{array}$ & $\begin{array}{l}0.4447(43) \\
0.6966(21) \\
1.4982(61)\end{array}$ & $\begin{array}{l}0.5696(13) \\
0.4485(50) \\
1.6729(61)\end{array}$ & $\begin{array}{l}0.3738(24) \\
0.3888(32) \\
1.6764(61)\end{array}$ & $\begin{array}{l}0.7953(27) \\
1.0035(49) \\
1.9586(61)\end{array}$ \\
\hline & Power loss (kW) & 40.28 & 9.545 & 34.28 & 72.65 \\
\hline & $\begin{array}{l}\text { Minimum voltage } \\
\text { (p.u.) }\end{array}$ & 0.9807 & 0.9875 & 0.9842 & 0.9625 \\
\hline & Loss reduction (\%) & 82.00 & 81.50 & 84.74 & 88.86 \\
\hline & $\Delta V_{D}$ (p.u.) & 0.0193 & 0.0125 & 0.0158 & 0.0375 \\
\hline & Iterations & 80 & 40 & 40 & 40 \\
\hline
\end{tabular}

Table 4 represents the comparison of results obtained by hybrid CS-GWO with different algorithms such as RGA [5], HSA [6], ACSA [14], GA [15], FWA [43], and UVDA [48].

- For scenario II, hybrid CS-GWO optimized NR with opened switches:69-20-12-56-61, with estimated PL and minimum voltage magnitude as $98.12 \mathrm{~kW}$ and $0.9495 \mathrm{p} . \mathrm{u}$, is approximately close to the obtained results from other methods compared.

- For scenario III (DGs installation only), hybrid CS-GWO obtained optimal location and sizing (MW) of DGs at buses $\{18,50,61\}$ and $\{0.5202,0.7509,1.7644\}$, respectively, to be installed for minimizing 
power losses and improving voltage profile. As a result, the proposed method provided the minimum PL and improved voltage profile compared with other methods.

- For scenario IV, the proposed method provides the optimal DGs sizes (MW) of $\{0.6950,0.5401$ and $1.2008\}$ for the installation at buses $\{64,12,61\}$. The PL obtained by the proposed method in this scenario is estimated to be minimal compared to other methods, i.e., $36.07 \mathrm{~kW}$ and improved voltage magnitude of 0.9834 p.u.

- For scenario V, the proposed method estimates optimal DNR along with DGs installation with opened switches: $13,56,69,24,18$, the optimal DGs installation at buses $\{24,32,61\}$ with sizes (MW) of $\{0.3738,0.3888$ and 1.6764$\}$, respectively. It is assessed that the PL obtained in this scenario by the proposed method is minimal compared to other methods, i.e., $34.28 \mathrm{~kW}$ and improved voltage magnitude of 0.9842 p.u.

Table 4. Comparison of results with other methods for the IEEE 69-bus system

\begin{tabular}{|c|c|c|c|c|c|c|c|c|}
\hline Scenario & Item & $\begin{array}{c}\text { FWA } \\
{[43]}\end{array}$ & $\begin{array}{c}\text { RGA } \\
{[5]}\end{array}$ & $\begin{array}{c}\text { GA } \\
{[15]}\end{array}$ & $\begin{array}{c}\text { HSA } \\
{[6]}\end{array}$ & $\begin{array}{c}\text { ACSA } \\
{[14]}\end{array}$ & $\begin{array}{c}\text { UVDA } \\
{[48]}\end{array}$ & $\begin{array}{l}\text { Proposed } \\
\text { CS-GWO }\end{array}$ \\
\hline \multirow[t]{3}{*}{$\begin{array}{c}\text { Base case } \\
(\text { Scenario I) }\end{array}$} & $\begin{array}{l}\text { Opened } \\
\text { switches }\end{array}$ & $\begin{array}{c}69,70,71, \\
72,73\end{array}$ & $\begin{array}{c}69,70 \\
71,72, \\
73\end{array}$ & $\begin{array}{c}69,70, \\
71,72,73\end{array}$ & $\begin{array}{c}69,70,71, \\
72,73\end{array}$ & $\begin{array}{c}69,70,71, \\
72,73\end{array}$ & $\begin{array}{c}69,70,71, \\
72,73\end{array}$ & $\begin{array}{c}69,70,71, \\
72,73\end{array}$ \\
\hline & $\begin{array}{c}\text { Power loss } \\
(\mathrm{kW})\end{array}$ & 224.89 & 224.89 & 224.89 & 225.00 & 224.89 & 224.89 & 224.70 \\
\hline & $\begin{array}{l}\text { Minimum } \\
\text { voltage } \\
\text { (p.u.) }\end{array}$ & 0.9092 & 0.9092 & 0.9092 & 0.9092 & 0.9092 & 0.9092 & 0.9094 \\
\hline \multirow{4}{*}{$\begin{array}{c}\text { Only } \\
\text { reconfigurati } \\
\text { on } \\
\text { (Scenario II) }\end{array}$} & $\begin{array}{l}\text { Opened } \\
\text { switches }\end{array}$ & $\begin{array}{c}60,70,14, \\
57,61\end{array}$ & $\begin{array}{c}69,17 \\
13, \\
55,61\end{array}$ & $\begin{array}{c}69,70,14 \\
53,61\end{array}$ & $\begin{array}{c}69,18,13 \\
56,61\end{array}$ & $\begin{array}{c}60,70,14, \\
57,61\end{array}$ & $\begin{array}{c}69,70,14, \\
58,61\end{array}$ & $\begin{array}{c}69,20,12,5 \\
6,61\end{array}$ \\
\hline & $\begin{array}{c}\text { Power loss } \\
(\mathrm{kW})\end{array}$ & 98.59 & 100.28 & 103.29 & 99.35 & 98.59 & 98.58 & 98.12 \\
\hline & $\begin{array}{l}\text { Minimum } \\
\text { voltage } \\
\text { (p.u.) }\end{array}$ & 0.9459 & 0.9428 & 0.9411 & 0.9428 & 0.9459 & 0.9495 & 0.9495 \\
\hline & $\begin{array}{l}\text { Loss } \\
\text { reduction } \\
(\%)\end{array}$ & 56.16 & 55.42 & 54.08 & 55.85 & 56.16 & 56.19 & 56.33 \\
\hline \multirow[t]{5}{*}{$\begin{array}{c}\text { Only DG } \\
\text { Installation } \\
\text { (Scenario III) }\end{array}$} & $\begin{array}{l}\text { Opened } \\
\text { switches }\end{array}$ & $\begin{array}{c}69,70,71 \\
72,73\end{array}$ & $\begin{array}{c}69,70 \\
71,72, \\
73\end{array}$ & $\begin{array}{c}69,70, \\
71,72,73\end{array}$ & $\begin{array}{c}69,70,71 \\
\quad 72,73\end{array}$ & $\begin{array}{c}69,70,71 \\
72,73\end{array}$ & $\begin{array}{c}69,70,71, \\
72,73\end{array}$ & $\begin{array}{c}69,70,71, \\
72,73\end{array}$ \\
\hline & $\begin{array}{c}\text { Size of } \\
\text { DG in } \\
\text { MW } \\
\text { (Bus } \\
\text { number) }\end{array}$ & $\begin{array}{c}0.4085(65 \\
) \\
1.1986(61 \\
) \\
0.2258(27 \\
)\end{array}$ & 1.7868 & 1.9471 & $\begin{array}{l}0.1018(65) \\
0.3690(64) \\
1.3024(63)\end{array}$ & $\begin{array}{c}0.6022(11) \\
0.3804(18) \\
2.000(61)\end{array}$ & $\begin{array}{c}1.410(61) \\
0.6040(11 \\
) \\
0.4170(17 \\
)\end{array}$ & $\begin{array}{c}0.5202(18 \\
) \\
0.7509(50 \\
) \\
1.7644(61 \\
)\end{array}$ \\
\hline & $\begin{array}{l}\text { Power loss } \\
(\mathrm{kW})\end{array}$ & 77.85 & 87.65 & 88.50 & 86.77 & 72.44 & 72.626 & 70.98 \\
\hline & $\begin{array}{l}\text { Minimum } \\
\text { voltage } \\
\text { (p.u.) }\end{array}$ & 0.9740 & 0.9678 & 0.9687 & 0.9677 & 0.9890 & 0.9688 & 0.9784 \\
\hline & $\begin{array}{l}\text { Loss } \\
\text { reduction } \\
(\%)\end{array}$ & 65.39 & 61.04 & 60.66 & 61.43 & 67.79 & 67.72 & 68.39 \\
\hline \multirow{3}{*}{$\begin{array}{c}\text { DG } \\
\text { installation } \\
\text { after } \\
\text { reconfigurati } \\
\text { on } \\
\text { (Scenario IV) }\end{array}$} & $\begin{array}{l}\text { Opened } \\
\text { switches }\end{array}$ & $\begin{array}{c}69,70,14 \\
57,61\end{array}$ & $\begin{array}{c}69,17 \\
16, \\
55,61\end{array}$ & $\begin{array}{c}69,70,14 \\
53,61\end{array}$ & $\begin{array}{c}69,18,13 \\
56,61\end{array}$ & $\begin{array}{c}69,70,14 \\
57,61\end{array}$ & $\begin{array}{c}69,70,14 \\
58,61\end{array}$ & $\begin{array}{c}69,14,70,6 \\
1,57\end{array}$ \\
\hline & $\begin{array}{l}\text { Size of } \\
\text { DG in } \\
\text { MW } \\
\text { (Bus } \\
\text { number) }\end{array}$ & $\begin{array}{c}1.7254(61 \\
) \\
0.4666(64 \\
) \\
0.3686(12 \\
)\end{array}$ & 1.6396 & 1.7422 & $\begin{array}{l}1.0666(61) \\
0.3525(60) \\
0.4257(58)\end{array}$ & $\begin{array}{l}1.7254(61) \\
0.4666(64) \\
0.3686(12)\end{array}$ & $\begin{array}{c}1.378(61) \\
0.6200(11 \\
) \\
0.7220(64 \\
)\end{array}$ & $\begin{array}{c}0.6950(64 \\
) \\
0.5401(12 \\
) \\
1.2008(61 \\
)\end{array}$ \\
\hline & $\begin{array}{c}\text { Power loss } \\
(\mathrm{kW})\end{array}$ & 37.23 & 52.34 & 54.53 & 51.30 & 37.23 & 37.84 & 36.07 \\
\hline
\end{tabular}




\begin{tabular}{|c|c|c|c|c|c|c|c|c|}
\hline & $\begin{array}{l}\text { Minimum } \\
\text { voltage } \\
\text { (p.u.) }\end{array}$ & 0.9870 & 0.9611 & 0.9401 & 0.9619 & 0.9870 & 0.9801 & 0.9834 \\
\hline & $\begin{array}{l}\text { Loss } \\
\text { reduction } \\
(\%)\end{array}$ & 83.45 & 76.73 & 75.76 & 77.20 & 83.45 & 83.18 & 83.94 \\
\hline \multirow{9}{*}{$\begin{array}{c}\text { Simultaneous } \\
\text { reconfigurati } \\
\text { on, DG } \\
\text { installation } \\
(\text { Scenario V) }\end{array}$} & $\begin{array}{l}\text { Opened } \\
\text { switches }\end{array}$ & $\begin{array}{c}69,70,12 \\
58,61\end{array}$ & $\begin{array}{c}10,16, \\
14, \\
55,62\end{array}$ & $\begin{array}{c}10,15,45, \\
55,62\end{array}$ & $\begin{array}{c}69,17,13 \\
58,61\end{array}$ & $\begin{array}{c}69,70,14 \\
58,61\end{array}$ & $\begin{array}{c}69,70,14 \\
58,63\end{array}$ & $\begin{array}{c}13,56,69 \\
24,18\end{array}$ \\
\hline & Size of & $1.749(61)$ & 2.0654 & 2.0292 & $1.0666(61)$ & $0.1566(62)$ & $0.5380(11$ & $0.3738(24$ \\
\hline & DG in & $0.1566(62$ & & & $0.3525(60)$ & $1.749(61)$ & ) & ) \\
\hline & MW & & & & $0.4527(62)$ & $0.4090(65)$ & $0.6730(17$ & $0.3888(32$ \\
\hline & (Bus & $0.4090(65$ & & & & & )$^{\prime}$ & )$^{(1641}$ \\
\hline & 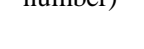 & & & & & & $1.4 / 2(01)$ & )$^{1.0704(01}$ \\
\hline & $\begin{array}{c}\text { Power loss } \\
(\mathrm{kW})\end{array}$ & 40.49 & 44.23 & 46.50 & 40.30 & 40.49 & 37.11 & 34.28 \\
\hline & $\begin{array}{l}\text { Minimum } \\
\text { voltage } \\
\text { (p.u.) }\end{array}$ & 0.9873 & 0.9742 & 0.9727 & 0.9736 & 0.9873 & 0.9816 & 0.9842 \\
\hline & $\begin{array}{l}\text { Loss } \\
\text { reduction } \\
(\%)\end{array}$ & 82.00 & 80.32 & 73.38 & 82.08 & 82.00 & 83.51 & 84.74 \\
\hline
\end{tabular}

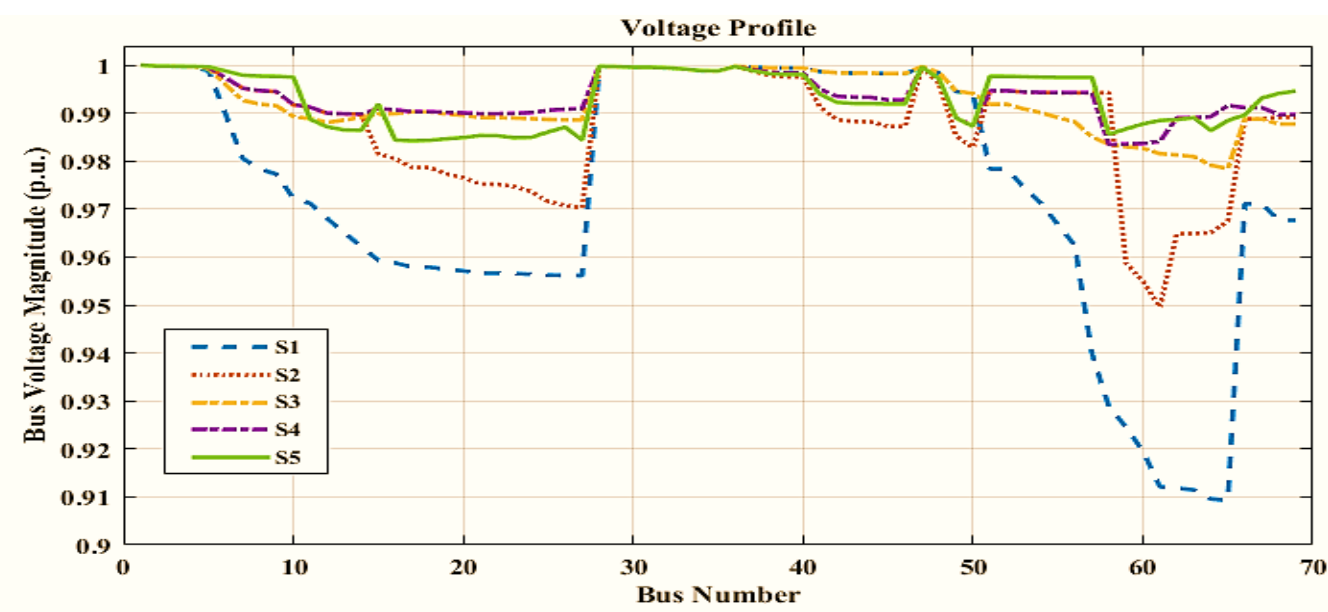

Figure 7. Voltage profile curves of an IEEE 69-bus system using hybrid CS-GWO algorithm

Convergence characteristics are also estimated for two scenarios II and V by considering the IEEE 69-bus system and depicted in Fig. 8a and 8b. From Fig. 8a at the $1^{\text {st }}$ iteration onwards, PL decreased from $110.00 \mathrm{~kW}$ to $98.12 \mathrm{~kW}$ for scenario II, and from Fig. $8 \mathrm{~b}$ at $30^{\text {th }}$ iteration onwards, PL decreased from 60.10 $\mathrm{kW}$ to $34.28 \mathrm{~kW}$ for scenario V. From Fig. 8a, it is found that the proposed hybrid CS-GWO technique has converged to an optimal solution after $3^{\text {rd }}$ iteration for scenario II, showing that by integrating cuckoo search in GWO algorithm may find a better solution within a short time of convergence process. Similarly, from Fig. $8 \mathrm{~b}$, it is found that the algorithm converges at the $30^{\text {th }}$ iteration providing an optimal solution with minimum PL in scenario V in comparison with other algorithms in the literature. The reduction in active PL obtained in the base case to those obtained from different scenarios for light, nominal and heavy load conditions is represented as a bar graph in Fig. 9. It can be noticed from Fig. 9 that the active PL (in $\mathrm{kW}$ ) in the base case for nominal load is 224.70 , and it is reduced drastically to $98.12,70.98,36.07,34.28$ for scenarios II, III, IV, $\mathrm{V}$, respectively.

From table 4, it is concluded that the PL reduction obtained by the proposed hybrid CS-GWO method is higher than that result with GA, UVDA, ACSA and FWA methods. From these results, the percentage PL reduction by the proposed hybrid CS-GWO method for scenarios II, III, IV, and V were 56.33\%, 68.39\%, $83.94 \%$, and $84.74 \%$, respectively. Whereas with GA, ACSA, UVDA and FWA, it is $\{54.08 \%, 60.66 \%$, $75.76 \%$, and $73.38 \%\} ;\{56.16 \%, 67.79 \%, 83.45 \%$, and $82.00 \%\} ;\{56.19 \%, 67.72 \%, 83.18 \%$, and $83.51 \%\}$ and $\{56.16 \%, 65.39 \%, 83.45 \%$, and $82.00 \%\}$ respectively. Hence the performance in terms of active PL minimization and voltage profile improvement, the proposed hybrid CS-GWO algorithm proved better performance for obtaining optimal solution when compared to the other optimization techniques. 


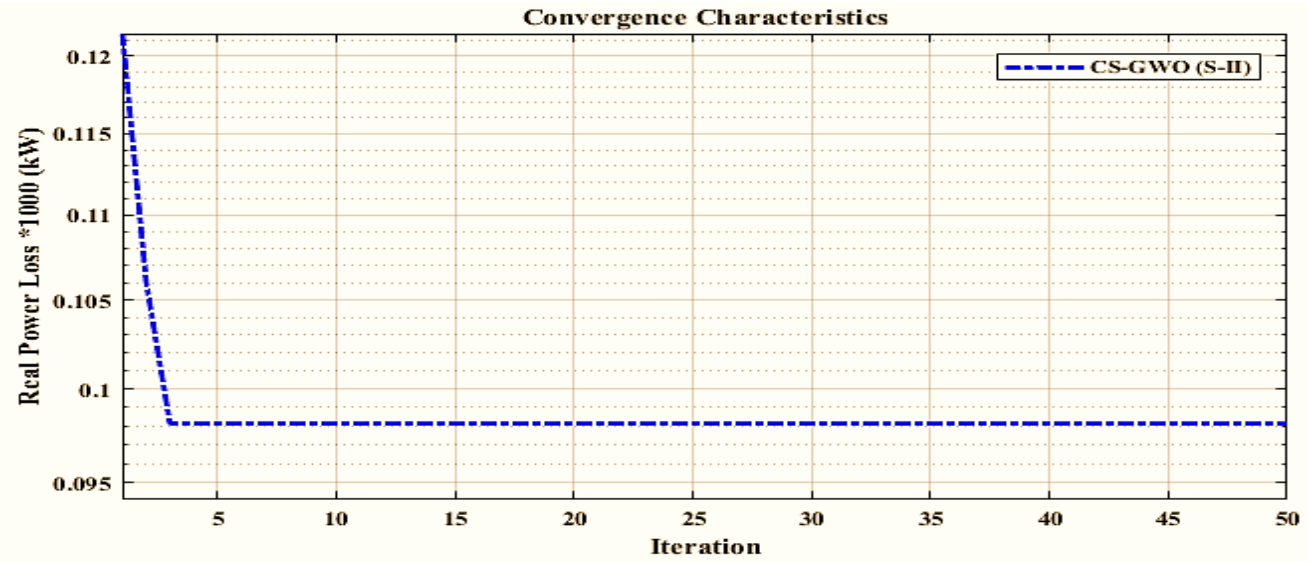

Figure 8a. Convergence characteristics for scenario II of IEEE 69-bus system using hybrid CS-GWO algorithm.

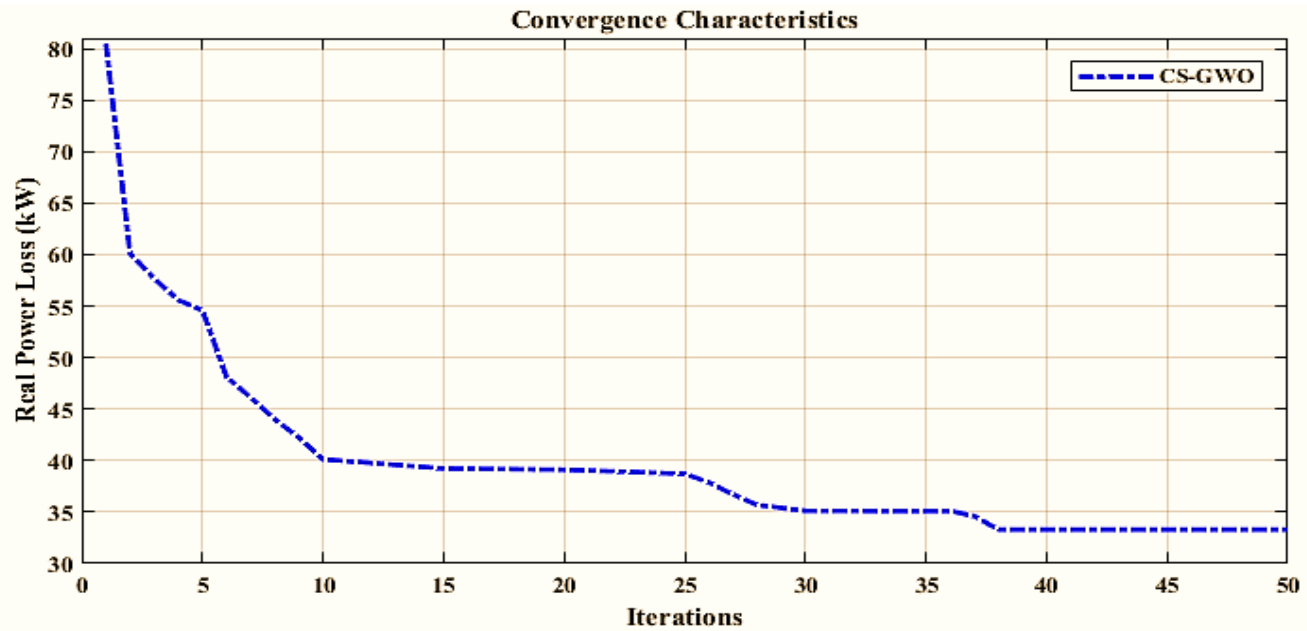

Figure 8b. Convergence characteristics for scenario V of IEEE 69-bus system using hybrid CS-GWO algorithm.

\section{Power Loss (kW)}

$\Delta$ Series1 $\mathrm{SSeries} 2 \mathrm{Series} 3$

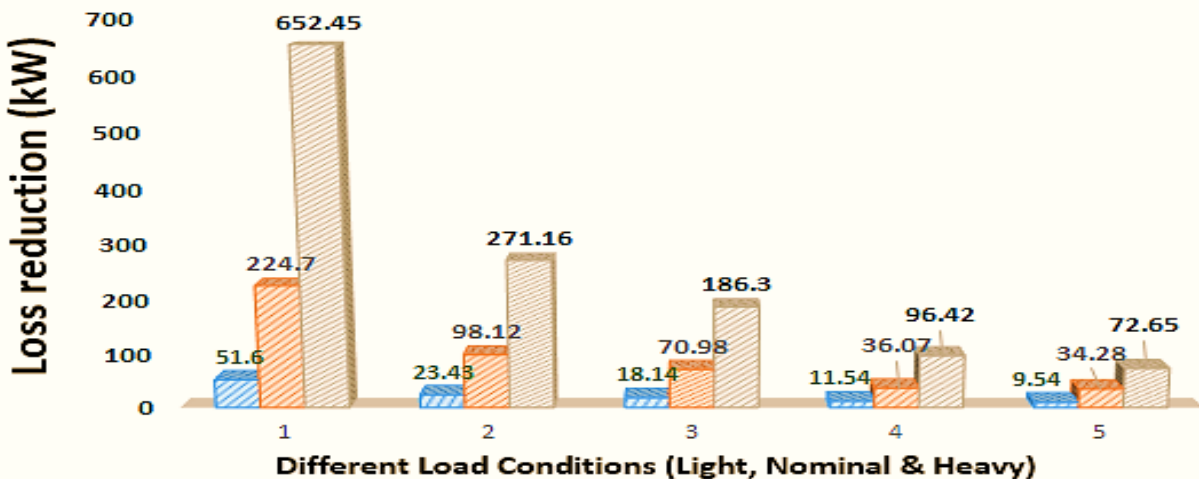

Figure 9. Power loss of an IEEE 69-bus system using CS-GWO algorithm under different loading conditions

Table 5 presents the assessment of the proposed CS-GWO algorithm for scenario $\mathrm{V}$ at nominal loading conditions and the results of the compared techniques. From this Table, it is observed that for scenario-V, 
simultaneously DNR with DG installation using the proposed algorithm has obtained an optimal solution that reduces power loss by $54.01 \mathrm{~kW}$, percentage power loss by $73.35 \%$, and enhanced minimum voltage magnitude (p.u) to 0.9865 for the 33-bus system and for the 69-bus system are $33.29 \mathrm{~kW}, 85.18 \%$ and 0.9842 under nominal load. The results show the effectiveness of the proposed algorithm over the conventional GWO and other earlier methods published. Therefore, the proposed CS-GWO method can be a promising method for dealing with the simultaneous DNR problem considering DG placement.

Table 5. Assessment of obtained results with previously published optimization algorithms for the IEEE 33,

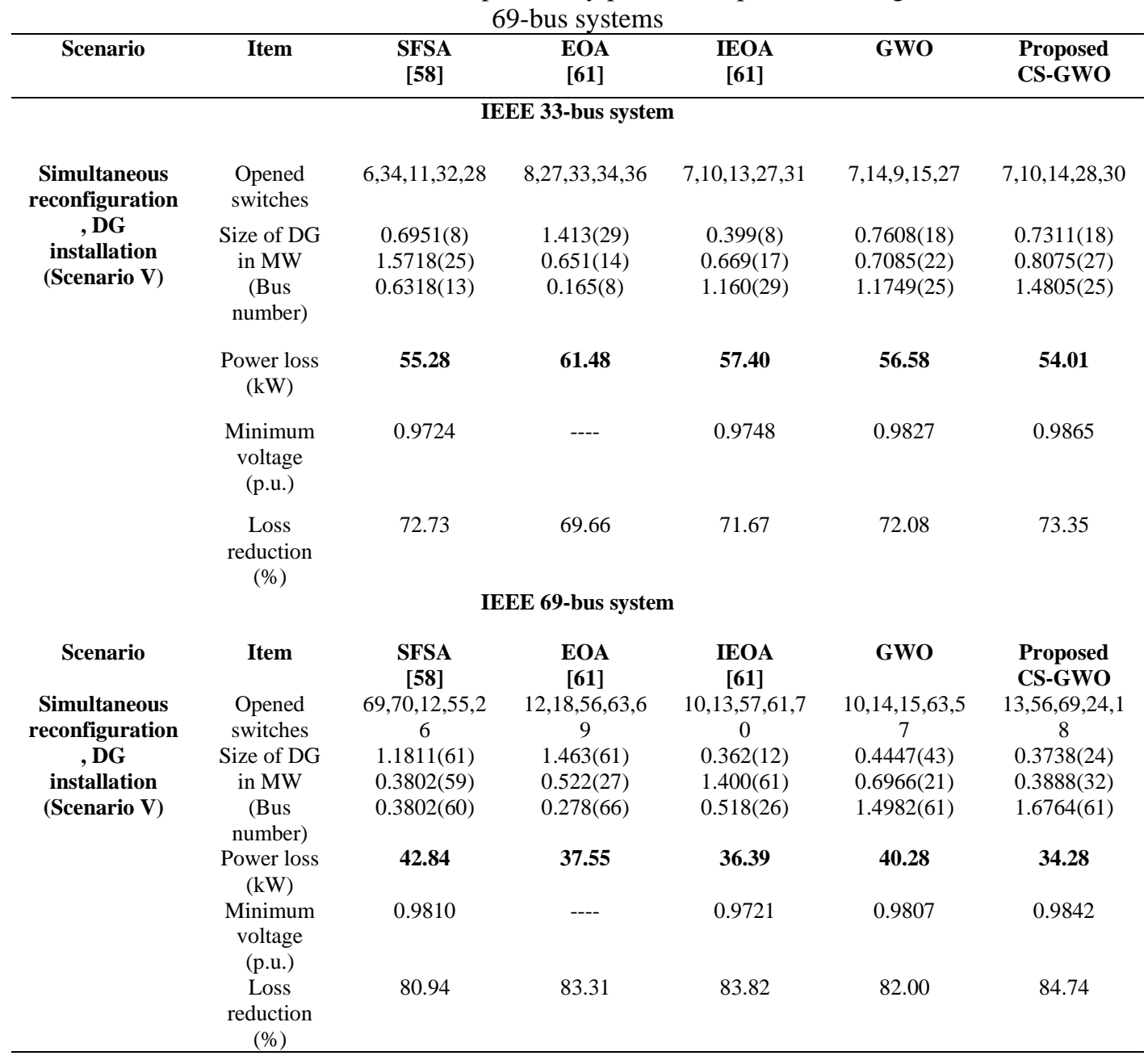

\section{CONCLUSION}

In this paper, the proposed hybrid CS-GWO algorithm has been implemented to simultaneously solve the DNR, DGs installation problem in the RDSs to reduce active power loss and voltage profile improvement. Moreover, different scenarios aimed at system loss reduction, voltage profile improvement and minimum voltage deviation were considered here.

- $\quad$ They are (i) Considering DNR only (S-II), estimated PL reduction solution by hybrid CS-GWO under nominal load is $139.55 \mathrm{~kW}$, along with minimum voltage magnitude and voltage deviation at load buses (p.u) is 0.9424 and 0.0576 for the IEEE 33-bus system, for the 69-bus system is 98.12 $\mathrm{kW}, 0.9495$ and 0.0505. Similarly, power reduction (S-V) for IEEE 33 and 69-bus systems is 54.01 $\mathrm{kW}$ and $34.28 \mathrm{~kW}$, respectively.

- Meanwhile, for scenario-V, simultaneously DNR with DG installation have obtained an optimal solution that reduces percentage power loss by $73.35 \%$ and enhanced minimum voltage magnitude (p.u) to 0.9865 for the 33-bus system and for the 69-bus system are $84.74 \%$ and 0.9842 under nominal load.

- Additionally, the percentage voltage improvement obtained by this proposed algorithm for scenarios II and III under nominal load is 3.11 and 7.45 for the IEEE 33-bus system. Similarly, for IEEE 69 bus is 4.22 and 7.60, respectively. 
- Analysis of the results obtained from the hybrid CS-GWO algorithm shows that simultaneous DNR, DG installation process in RDSs is a more effective method in minimizing system power loss and improving the system's voltage profile than results obtained by other optimization methods reported earlier in the literature.

The results obtained by the proposed hybrid CS-GWO algorithm are compared with other optimization techniques such as HSA, GA, RGA, FWA, ACSA, UVDA, SFS and MPGSA. The comparison validates the effectiveness of the proposed technique shows that it is a better and promising method than the other optimization approaches in solving DNR, DGs installation problems simultaneously. Therefore, the proposed hybrid CS-GWO algorithm may be treated as a constructive method for optimizing DNR problem for complex and large-scale RDS and optimal location and sizing of the installed DGs.

APPENDIX:

Table A1. Summary of recently published works to solve DNR problem considering DGs

\begin{tabular}{|c|c|c|}
\hline $\begin{array}{l}\text { Author, } \\
\text { Year, } \\
\text { [Ref.] }\end{array}$ & $\begin{array}{l}\text { Optimization } \\
\text { algorithm/technique }\end{array}$ & Objective function \\
\hline $\begin{array}{l}\text { A. M. } \\
\text { Shaheen, } \\
\text { et.al., 2021, } \\
\text { [61] }\end{array}$ & $\begin{array}{l}\text { Equilibrium } \\
\text { Optimization } \\
\text { Algorithm (IEOA) }\end{array}$ & $\begin{array}{l}\text { To minimize the total power } \\
\text { losses (TPL) and maximize } \\
\text { the total voltage stability } \\
\text { index (TVSI) }\end{array}$ \\
\hline $\begin{array}{l}\text { Dieu Vo } \\
\text { Ngoc, et.al., } \\
2020,[66]\end{array}$ & $\begin{array}{l}\text { Chaotic Stochastic } \\
\text { Fractal Search } \\
\text { Algorithm } \\
\text { (CSFSA) }\end{array}$ & $\begin{array}{l}\text { To minimize the APL and } \\
\text { improve the voltage profile. }\end{array}$ \\
\hline $\begin{array}{l}\text { Ayodeji } \\
\text { Olalekan } \\
\text { Salau et.al., } \\
2020,[73]\end{array}$ & $\begin{array}{l}\text { Modified Selective } \\
\text { particle swarm } \\
\text { optimization } \\
\text { (SPSO) method }\end{array}$ & $\begin{array}{l}\text { To minimize the power loss } \\
\text { and improve the voltage } \\
\text { profile. }\end{array}$ \\
\hline $\begin{array}{l}\text { T } \\
\text { Jayabarathi, } \\
\text { et.al., 2020, } \\
\text { [74] }\end{array}$ & $\begin{array}{l}\text { Grasshopper } \\
\text { optimization } \\
\text { algorithm (GOA) }\end{array}$ & $\begin{array}{l}\text { Power loss minimization and } \\
\text { voltage profile (VP) } \\
\text { enhancement in RDSs under } \\
\text { different loading conditions. }\end{array}$ \\
\hline $\begin{array}{l}\text { Ayodeji } \\
\text { Olalekan }\end{array}$ & $\begin{array}{l}\text { Grid based Multi- } \\
\text { Objective Harmony }\end{array}$ & $\begin{array}{l}\text { To optimally size and locate } \\
\text { the DG on the feeder resulting }\end{array}$ \\
\hline $\begin{array}{l}\text { Salau et.al., } \\
2020,[75]\end{array}$ & $\begin{array}{l}\text { Search Algorithm } \\
\text { (GrMHSA) }\end{array}$ & $\begin{array}{l}\text { in lowest total voltage } \\
\text { deviation, total active and } \\
\text { reactive power loss. }\end{array}$ \\
\hline $\begin{array}{l}\text { Ayodeji } \\
\text { Olalekan } \\
\text { Salau et.al., } \\
2020,[76]\end{array}$ & $\begin{array}{l}\text { Grid-Based Multi- } \\
\text { Objective Harmony } \\
\text { Search Algorithm } \\
\text { (GrMHSA) }\end{array}$ & $\begin{array}{l}\text { To mitigate power losses and } \\
\text { improve the voltage profile by } \\
\text { the optimal sizing and placing } \\
\text { of DGs in the distribution } \\
\text { network. }\end{array}$ \\
\hline
\end{tabular}

$\begin{array}{lll}\begin{array}{l}\text { A.Selim, } \\ \text { et.al., 2021, } \\ \text { [77] }\end{array} & \begin{array}{l}\text { Modified Whale } \\ \text { Optimization } \\ \text { (MOWOA) } \\ \text { algorithm and fuzzy } \\ \text { decision-making } \\ \text { method }\end{array} & \begin{array}{l}\text { Power loss and voltage } \\ \text { deviation (VD) minimization } \\ \text { and voltage stability index } \\ \text { (VSI) optimize. }\end{array} \\ \begin{array}{l}\text { Fuzzy Expert } \\ \text { Olalekan }\end{array} & \begin{array}{l}\text { System (FES) } \\ \text { method }\end{array} & \begin{array}{l}\text { To determine the voltage } \\ \text { regulator (VR) and capacitor } \\ \text { placement suitability index. }\end{array} \\ \text { 2021, [78] } & \begin{array}{l}\text { (Fuzzy logic } \\ \text { optimization } \\ \text { method) }\end{array} & \\ & & \end{array}$

- IEEE 33,69 and 137-bus test system.

- Obtain optimal global solutions for complex combinatorial problems.

- Effective method having better controllability between exploration and exploitation.

- 33,84,119 and 136 RDSs.

- Favorable method for solving complex and large-scale DNR problem.

- Integration of chaos theory in SFSA has improved diffusing efficiency, updating process, and search ability.

-33 RDSs.

-the proposed method has been found to be more efficient in reducing voltage deviation (VD) and power losses in the system.

-the proposed algorithm was efficient in terms of reducing both the real and reactive power losses in the system.

- 33,69 and 118 RDSs.

- Effective method for solving complex and large-scale DNR problem in presences of DSTATCOM units and PV arrays.

- Debre Markos Feeder 3.

- The results showed that the total voltage deviation, active and reactive power losses are reduced to 1.479 p. u, $95.398 \mathrm{~kW}$ and 90.979 kVAR, respectively.

- Utility feeder 4 test system.

- The performance comparison of GrMHSA and MOPSO showed that GrMHSA performs better in terms of reducing voltage deviation and power losses in the system.

- The results showed that the total voltage deviation, active and reactive power losses were reduced by $85.20 \%, 84.94 \%$, and $85.73 \%$, respectively.

- IEEE 33,69-bus test system.

- Competitive optimization algorithm having minimum convergences rate.

- An effective method for finding optimal DGs placement and size in the system based on the fuzzy decision-making process.

- Gondar feeder in Gondar, Ethiopia (60 nodes RDS).

- The results indicate that by using capacitors, $159.85 \mathrm{KW}$ power is saved and also in the same way all the weak bus VPs are optimized to the standard $\pm 5 \%$ voltage deviation level.

- The total real PL reduction is $38.46 \%$ using VRs and $42.316 \%$ using shunt capacitors. 


\begin{tabular}{|c|c|c|c|}
\hline $\begin{array}{l}\text { Ahmad Eid, } \\
\text { et.al., 2021, } \\
\text { [79] }\end{array}$ & $\begin{array}{l}\text { Manta-Ray } \\
\text { Foraging } \\
\text { Optimization } \\
\text { (MRFO) algorithm }\end{array}$ & $\begin{array}{l}\text { To reduce the total energy } \\
\text { loss of system }\end{array}$ & $\begin{array}{l}\text { - IEEE 69-bus test system. } \\
\text { - Have capable of optimizing the size, site, and } \\
\text { power factor of every DG along the 24-hour } \\
\text { cycle to minimize system losses. } \\
\text { - An effective method for finding optimal DGs } \\
\text { placement and size in system considering time- } \\
\text { varying demands and different operating DG } \\
\text { power factor. }\end{array}$ \\
\hline $\begin{array}{l}\text { M. } \\
\text { Khasanov, } \\
\text { et.al., 2021, } \\
\text { [80] }\end{array}$ & $\begin{array}{l}\text { Rider Optimization } \\
\text { Algorithm }\end{array}$ & $\begin{array}{l}\text { To minimize total power and } \\
\text { energy losses }\end{array}$ & $\begin{array}{l}\text { - IEEE 33,69-bus test system. } \\
\text { functions are used to characterize the variability } \\
\text { of renewable potentials. } \\
\text { - An effective approach for finding optimal } \\
\text { renewable DGs placement and size in system } \\
\text { considering time-varying load demand and } \\
\text { probabilistic generation. }\end{array}$ \\
\hline $\begin{array}{l}\text { K. Balu, } \\
\text { et.al., 2021, } \\
\text { [81] }\end{array}$ & $\begin{array}{c}\text { Student } \\
\text { Psychology-Based } \\
\text { Optimization } \\
\text { Algorithm }\end{array}$ & $\begin{array}{l}\text { To minimize APL, total } \\
\text { voltage deviation and voltage } \\
\text { stability index of the RDSs } \\
\text { consider different load } \\
\text { models. }\end{array}$ & $\begin{array}{l}\text { - IEEE } 33,69 \text { and brazilian } 136 \text {-bus test system. } \\
\text { - The analytic hierarchy process is used to } \\
\text { optimize the weighting factor. } \\
\text { - An effective method to solve the optimal } \\
\text { multiple DG allocation problem with minimum } \\
\text { real power loss, less computational time, and a } \\
\text { prominent convergence rate. }\end{array}$ \\
\hline I. & Atom Search & To minimize power losses & - IEEE 33-bus test system. \\
\hline $\begin{array}{l}\text { Khonturaev, } \\
\text { et.al., 2021, } \\
\text { [82] }\end{array}$ & $\begin{array}{l}\text { Optimization } \\
\text { Algorithm }\end{array}$ & & $\begin{array}{l}\text { - Power loss sensitivity index method is used to } \\
\text { find optimal buses for DGs installation. } \\
\text { - An effective approach for finding optimal DGs } \\
\text { placement and size in system. }\end{array}$ \\
\hline
\end{tabular}

\section{DECLARATION OF COMPETING INTEREST}

The authors declare that they have no known competing financial interests or personal relationships that could have appeared to influence the work reported in this paper.

\section{FUNDING INFORMATION}

This research did not receive any specific grant from funding agencies in the public, commercial, or not-forprofit sectors.

\section{ACKNOWLEDGMENT}

The authors are extremely grateful to the chancellor, vice-chancellor, Vellore institute of technology, Vellore for providing the excellent infrastructure facilities and encouragement which have made this research work possible.

\section{REFERENCES}

[1] Roosta, A., Eskandari, HR. \& Khooban, MH. Optimization of radial unbalanced distribution networks in the presence of distribution generation units by network reconfiguration using harmony search algorithm. Neural Comput \& Applic 31, 7095-7109 (2019).

[2] Shilpa Kalambe, Ganga Agnihotri, Loss minimization techniques used in distribution network: bibliographical survey, Renewable and Sustainable Energy Reviews, Volume 29, 2014, Pages 184-200.

[3] Merlin, A. (1975). Search for a minimal-loss operating spanning tree configuration for an urban power distribution system. Proc. of 5th PSCC, 1975, 1, 1-18.

[4] Civanlar S, Grainger JJ, Le SSH. Distribution feeder reconfiguration for loss reduction. IEEE Trans, Power Deliv 1988:3:1217-23.

[5] Zhu, Ji Zhong. "Optimal reconfiguration of electrical distribution network using the refined genetic algorithm." Electric Power Systems Research 62.1 (2002): 37-42.

[6] Rao, R. S., Narasimham, S. V. L., Raju, M. R., \& Rao, A. S. (2010). Optimal network reconfiguration of large-scale distribution system using harmony search algorithm. IEEE Transactions on power systems, 26(3), 1080-1088.

[7] Zin, A. A. M., Ferdavani, A. K., Khairuddin, A. B., \& Naeini, M. M. (2011). Reconfiguration of radial electrical distribution network through minimum-current circular-updating-mechanism method. IEEE Transactions on Power Systems, 27(2), 968-974.

[8] M.-R. Haghifam, J. Olamaei, and M.-R. Andervazh, "Adaptive multi-objective distribution network reconfiguration using multi-objective discrete particles swarm optimisation algorithm and graph theory," IET Generation, Transmission \& Distribution, vol. 7, no. 12, pp. 1367-1382, 2013.

[9] Mirhoseini, Seyed Hasan, et al. "A new improved adaptive imperialist competitive algorithm to solve the reconfiguration problem of distribution systems for loss reduction and voltage profile improvement." International Journal of Electrical Power \& Energy Systems 55 (2014): 128-143. 
[10] Kumar, K. Sathish, and S. Naveen. "Power system reconfiguration and loss minimization for a distribution system using "Catfish PSO" algorithm." Frontiers in Energy 8.4 (2014): 434-442.

[11] Imran, A. Mohamed, and M. Kowsalya. "A new power system reconfiguration scheme for power loss minimization and voltage profile enhancement using fireworks algorithm." International Journal of Electrical Power \& Energy Systems 62 (2014): 312-322.

[12] Duan, Dong-Li, et al. "Reconfiguration of distribution network for loss reduction and reliability improvement based on an enhanced genetic algorithm." International Journal of Electrical Power \& Energy Systems 64 (2015): 88-95.

[13] Vitorino, Romeu M., Humberto M. Jorge, and Luís P. Neves. "Multi-objective optimization using NSGA-II for power distribution system reconfiguration." International Transactions on Electrical Energy Systems 25.1 (2015): 38-53.

[14] Nguyen, Thuan Thanh, and Anh Viet Truong. "Distribution network reconfiguration for power loss minimization and voltage profile improvement using cuckoo search algorithm." International Journal of Electrical Power \& Energy Systems 68 (2015): 233-242.

[15] K. Nara, A. Shiose, M. Kitagawoa, and T. Ishihara, Implementation of genetic algorithm for distribution systems loss minimum reconfiguration, IEEE Trans. Power Syst., 7(3), (1992), 1044-1051.

[16] Nguyen, Thuan Thanh, et al. "Multi-objective electric distribution network reconfiguration solution using runnerroot algorithm." Applied Soft Computing 52 (2017): 93-108.

[17] de Faria, H., Mauricio GC Resende, and D. Ernst. "A biased random key genetic algorithm applied to the electric distribution network reconfiguration problem." Journal of Heuristics 23.6 (2017): 533-550.

[18] A. A. Firdaus, O. Penangsang, and A. Soeprijanto, "Distribution network reconfiguration using binary particle swarm optimization to minimize losses and decrease voltage stability index," Bulletin of Electrical Engineering and Informatics, vol. 7, no. 4, pp. 514-521, 2018.

[19] Verma, H. K., \& Singh, P. (2018). Optimal reconfiguration of distribution network using modified culture algorithm. Journal of The Institution of Engineers (India): Series B, 99(6), 613-622.

[20] Landeros, Alberto, Slawomir Koziel, and Mohamed F. Abdel-Fattah. "Distribution network reconfiguration using feasibility-preserving evolutionary optimization." Journal of Modern Power Systems and Clean Energy 7.3 (2019): 589-598.

[21] Mohamed Diaaeldin, I., Abdel Aleem, S. H., El-Rafei, A., Abdelaziz, A. Y., \& Zobaa, A. F. (2019). A novel graphically-based network reconfiguration for power loss minimization in large distribution systems. Mathematics, $7(12), 1182$

[22] Moradi, Mohammad Hasan, and M. Abedini. "A combination of genetic algorithm and particle swarm optimization for optimal DG location and sizing in distribution systems." International Journal of Electrical Power \& Energy Systems 34.1 (2012): 66-74.

[23] Devi, S., and M. Geethanjali. "Application of modified bacterial foraging optimization algorithm for optimal placement and sizing of distributed generation." Expert Systems with Applications 41.6 (2014): 2772-2781.

[24] Viral, Rajkumar, and Dheeraj K. Khatod. "An analytical approach for sizing and siting of DGs in balanced radial distribution networks for loss minimization." International Journal of Electrical Power \& Energy Systems 67 (2015): 191-201.

[25] Prabha, D. Rama, and T. Jayabarathi. "Optimal placement and sizing of multiple distributed generating units in distribution networks by invasive weed optimization algorithm." Ain Shams Engineering Journal 7.2 (2016): 683694.

[26] Sultana, Sneha, and Provas Kumar Roy. "Multi-objective quasi-oppositional teaching learning based optimization for optimal location of distributed generator in radial distribution systems." International Journal of Electrical Power \& Energy Systems 63 (2014): 534-545.

[27] Prabha, D. Rama, et al. "Optimal location and sizing of distributed generation unit using intelligent water drop algorithm." Sustainable Energy Technologies and Assessments 11 (2015): 106-113.

[28] Sultana, Sneha, and Provas Kumar Roy. "Krill herd algorithm for optimal location of distributed generator in radial distribution system." Applied Soft Computing 40 (2016): 391-404.

[29] Reddy, P. D. P., Reddy, V. V., \& Manohar, T. G. (2016). Application of flower pollination algorithm for optimal placement and sizing of distributed generation in distribution systems. Journal of Electrical Systems and Information Technology, 3(1), 14-22.

[30] Yammani, Chandrasekhar, Sydulu Maheswarapu, and Sailaja Kumari Matam. "A Multi-objective Shuffled Bat algorithm for optimal placement and sizing of multi distributed generations with different load models." International Journal of Electrical Power \& Energy Systems 79 (2016): 120-131.

[31] ChithraDevi, S. A., L. Lakshminarasimman, and R. Balamurugan. "Stud Krill herd Algorithm for multiple DG placement and sizing in a radial distribution system." Engineering Science and Technology, an International Journal 20.2 (2017): 748-759.

[32] Mohamed, M. A., Elnozahy, A. H. M. E. D., \& Abdelaziz, A. Y. (2018). Optimal energy saving of photovoltaic distributed generation system with considering environment condition via hyper-spherical search algorithm. WSEAS Transactions on Power Systems, 13, 311-325.

[33] Suresh, M. C. V., and Belwin J. Edward. "Optimal placement of DG units for loss reduction in distribution systems using one rank cuckoo search algorithm." International Journal of Grid and Distributed Computing 11.1 (2018): 37 44.

[34] Nguyen, Tri Phuoc, and Dieu Ngoc Vo. "Optimal number, location, and size of distributed generators in distribution systems by symbiotic organism search-based method." Advances in Electrical and Electronic Engineering 15.5 (2018): 724-735. 
[35] Nguyen, Tri Phuoc, and Dieu Ngoc Vo. "A novel stochastic fractal search algorithm for optimal allocation of distributed generators in radial distribution systems." Applied Soft Computing 70 (2018): 773-796.

[36] Jamil Mahfoud, R., Sun, Y., Faisal Alkayem, N., Haes Alhelou, H., Siano, P., \& Shafie-khah, M. (2019). A novel combined evolutionary algorithm for optimal planning of distributed generators in radial distribution systems. Applied Sciences, 9(16), 3394.

[37] Gholami, Khalil, and Mohammad Hasan Parvaneh. "A mutated salp swarm algorithm for optimum allocation of active and reactive power sources in radial distribution systems." Applied Soft Computing 85 (2019): 105833.

[38] Nowdeh, S. Arabi, et al. "Fuzzy multi-objective placement of renewable energy sources in distribution system with objective of loss reduction and reliability improvement using a novel hybrid method." Applied Soft Computing 77 (2019): 761-779.

[39] El-Ela, A. A. A., El-Sehiemy, R. A., Shaheen, A. M., \& Ellien, A. R. (2020). Optimal allocation of distributed generation units correlated with fault current limiter sites in distribution systems. IEEE Systems Journal

[40] Naderipour, A., Nowdeh, S. A., Saftjani, P. B., Abdul-Malek, Z., Mustafa, M. W. B., Kamyab, H., \& Davoudkhani, I. F. (2021). Deterministic and probabilistic multi-objective placement and sizing of wind renewable energy sources using improved spotted hyena optimizer. Journal of Cleaner Production, 286, 124941.

[41] Rao, R. Srinivasa, et al. "Power loss minimization in distribution system using network reconfiguration in the presence of distributed generation." IEEE transactions on power systems 28.1 (2012): 317-325.

[42] Abdelaziz, A. Y., Reham A. Osama, and S. M. El-Khodary. "Reconfiguration of distribution systems for loss reduction using the hyper-cube ant colony optimisation algorithm." IET generation, transmission \& distribution 6.2 (2012): 176-187.

[43] Imran, A. Mohamed, M. Kowsalya, and D. P. Kothari. "A novel integration technique for optimal network reconfiguration and distributed generation placement in power distribution networks." International Journal of Electrical Power \& Energy Systems 63 (2014): 461-472.

[44] Rajaram, R., K. Sathish Kumar, and N. Rajasekar. "Power system reconfiguration in a radial distribution network for reducing losses and to improve voltage profile using modified plant growth simulation algorithm with Distributed Generation (DG)." Energy Reports 1 (2015): 116-122.

[45] T. T. Nguyen, A. V. Truong, and T. A. Phung, "A novel method based on adaptive cuckoo search for optimal network reconfiguration and distributed generation allocation in distribution network," International Journal of Electrical Power \& Energy Systems, vol. 78, pp. 801-815, 2016.

[46] Hormozi, Mohammad Ali, Mohammad Barghi Jahromi, and Gholamreza Nasiri. "Optimal network reconfiguration and distributed generation placement in distribution system using a hybrid algorithm." International Journal of Energy and Power Engineering Volume 5, Issue 5, October 2016, Pages: 163-170.

[47] Mahboubi-Moghaddam, Esmaeil, et al. "Multi-objective distribution feeder reconfiguration to improve transient stability, and minimize power loss and operation cost using an enhanced evolutionary algorithm at the presence of distributed generations." International Journal of Electrical Power \& Energy Systems 76 (2016): 35-43.

[48] Bayat, Akbar, A. Bagheri, and R. Noroozian. "Optimal siting and sizing of distributed generation accompanied by reconfiguration of distribution networks for maximum loss reduction by using a new UVDA-based heuristic method." International Journal of Electrical Power \& Energy Systems 77 (2016): 360-371.

[49] Aman, Muhammad Mohsin, Ghauth B. Jasmon, and Hazlee Mokhlis. "Optimum tie switches allocation and DG placement based on maximisation of system loadability using discrete artificial bee colony algorithm." IET Generation, Transmission \& Distribution 10.10 (2016): 2277-2284.

[50] Muthukumar, K., and S. Jayalalitha. "Integrated approach of network reconfiguration with distributed generation and shunt capacitors placement for power loss minimization in radial distribution networks." Applied Soft Computing 52 (2017): 1262-1284.

[51] Singh, N., \& Singh, S. B. (2017). A novel hybrid GWO-SCA approach for optimization problems. Engineering Science and Technology, an International Journal, 20(6), 1586-1601.

[52] Heidari, Mohammad Amin. "Optimal network reconfiguration in distribution system for loss reduction and voltageprofile improvement using hybrid algorithm of PSO and ACO." CIRED-Open Access Proceedings Journal 2017.1 (2017): 2458-2461.

[53] Quadri, Imran Ahmad, Suman Bhowmick, and Dheeraj Joshi. "Multi-objective approach to maximise loadability of distribution networks by simultaneous reconfiguration and allocation of distributed energy resources." IET Generation, Transmission \& Distribution 12.21 (2018): 5700-5712.

[54] El-salam, A., Fouad, M., Beshr, E., \& Eteiba, M. B. (2018). A new hybrid technique for minimizing power losses in a distribution system by optimal sizing and siting of distributed generators with network reconfiguration. Energies, 11(12), 3351.

[55] Hamida, Imen Ben, et al. "Optimal network reconfiguration and renewable DG integration considering time sequence variation in load and DGs." Renewable energy 121 (2018): 66-80.

[56] Onlam, A., Yodphet, D., Chatthaworn, R., Surawanitkun, C., Siritaratiwat, A., \& Khunkitti, P. (2019). Power loss minimization and voltage stability improvement in electrical distribution system via network reconfiguration and distributed generation placement using novel adaptive shuffled frogs leaping algorithm. Energies, 12(3), 553.

[57] Rafi, V., \& Dhal, P. K. (2020). Maximization savings in distribution networks with optimal location of type-I distributed generator along with reconfiguration using PSO-DA optimization techniques. Materials Today: Proceedings, 33, 4094-4100.

[58] Tran, Tung The, Khoa Hoang Truong, and Dieu Ngoc Vo. "Stochastic fractal search algorithm for reconfiguration of distribution networks with distributed generations." Ain Shams Engineering Journal 11.2 (2020): 389-407. 
[59] Essallah, Sirine, and Adel Khedher. "Optimization of distribution system operation by network reconfiguration and DG integration using MPSO algorithm." Renewable Energy Focus 34 (2020): 37-46.

[60] Quoc, S. N., \& Ngoc, D. V. (2020). Symbiotic Organism Search Algorithm for Power Loss Minimization in Radial Distribution Systems by Network Reconfiguration and Distributed Generation Placement. Mathematical Problems in Engineering, 2020.

[61] Shaheen, A. M., Elsayed, A. M., El-Sehiemy, R. A., \& Abdelaziz, A. Y. (2021). Equilibrium optimization algorithm for network reconfiguration and distributed generation allocation in power systems. Applied Soft Computing, 98, 106867.

[62] Diaaeldin, I. M., Aleem, S. H. A., El-Rafei, A., Abdelaziz, A. Y., \& calasan, M. (2020, February). Optimal network reconfiguration and distributed generation allocation using Harris Hawks optimization. In 2020 24th International Conference on Information Technology (IT) (pp. 1-6). IEEE.

[63] Jafar-Nowdeh, Ali, et al. "Meta-heuristic matrix moth-flame algorithm for optimal reconfiguration of distribution networks and placement of solar and wind renewable sources considering reliability." Environmental Technology \& Innovation 20 (2020): 101118.

[64] Kaveh, Mohammad Reza, Rahmat-Allah Hooshmand, and Seyed M. Madani. "Simultaneous optimization of rephasing, reconfiguration and DG placement in distribution networks using BF-SD algorithm." Applied Soft Computing 62 (2018): 1044-1055.

[65] Ghosh, S., \& Sherpa, K. S. (2008). An efficient method for load-flow solution of radial distribution networks. Int. J. Elect. Power Energy Syst. Eng, 1(2), 108-115.

[66] Vo Ngoc, D., \& Tran Anh, N. (2020). Distribution network reconfiguration for power loss reduction and voltage profile improvement using chaotic stochastic fractal search algorithm. Complexity, 2020.

[67] S. Mirjalili,A.lewis ,Grey Wolf Optimizer, Advances in Engineering Software, 69, (2014), 46-61.

[68] Yang, X. S., \& Deb, S. (2009, December). Cuckoo search via Lévy flights. In 2009 World congress on nature \& biologically inspired computing (NaBIC) (pp. 210-214). Ieee.

[69] Xu, Hui, Xiang Liu, and Jun Su. "An improved grey wolf optimizer algorithm integrated with Cuckoo Search." In 2017 9th IEEE international conference on intelligent data acquisition and advanced computing systems: technology and applications (IDAACS), vol. 1, pp. 490-493. IEEE, 2017.

[70] Abhishek Gupta (2021). Hybrid Grey Wolf and Cuckoo Search Optimization Algorithm (https://www.mathworks.com/matlabcentral/fileexchange/69392-hybrid-grey-wolf-and-cuckoo-search- ptimizationalgorithm), MATLAB Central File Exchange. Retrieved december 22, 2020.

[71] Baran, M. E., \& Wu, F. F. (1989). Network reconfiguration in distribution systems for loss reduction and load balancing. IEEE Power Engineering Review, 9(4), 101-102.

[72] Chiang H, Jean-Jumeau R. Optimal network reconfigurations in distribution systems. I. A new formulation and a solution methodology. IEEE Trans Power Deliv 1990; 5:1902-9.

[73] Salau, A. O., Gebru, Y. W., \& Bitew, D. (2020). Optimal network reconfiguration for power loss minimization and voltage profile enhancement in distribution systems. Heliyon, 6(6), e04233.

[74] Sambaiah, K. S., \& Jayabarathi, T. (2020). Optimal Reconfiguration of Distribution Network in Presence of DSTATCOM and Photovoltaic Array using a Metaheuristic Algorithm. European Journal of Electrical Engineering and Computer Science, 4(5).

[75] Agajie, T. F., Salau, A. O., Hailu, E. A., Sood, M., \& Jain, S. (2019, October). Optimal sizing and siting of distributed generators for minimization of power losses and voltage deviation. In 2019 5th International Conference on Signal Processing, Computing and Control (ISPCC) (pp. 292-297). IEEE.

[76] Ferede, A. T., Olalekan, S. A., Abel, H. E., \& Ayalew, A. Y. (2020). Power loss mitigation and voltage profile improvement with distributed generation using grid-based multi-objective harmony search algorithm. Journal of Electrical and Electronics Engineering, 13(2), 5-10.

[77] Selim, A., Kamel, S., \& Jurado, F. (2021). Fuzzy-Based Optimal Integration of Multiple Distributed Generations. In Applications of Fuzzy Logic in Planning and Operation of Smart Grids (pp. 1-22). Springer, Cham.

[78] Addisu, M., Salau, A. O., \& Takele, H. (2021). Fuzzy logic based optimal placement of voltage regulators and capacitors for distribution systems efficiency improvement. Heliyon, 7(8), e07848.

[79] Eid, A., Abdelaziz, A. Y., \& Dardeer, M. (2021). Energy Loss Reduction of Distribution Systems Equipped with Multiple Distributed Generations Considering Uncertainty using Manta-Ray Foraging Optimization. International Journal of Renewable Energy Development, 10(4), 779-787.

[80] Khasanov, M., Kamel, S., Rahmann, C., Hasanien, H. M., \& Al-Durra, A. (2021). Optimal distributed generation and battery energy storage units integration in distribution systems considering power generation uncertainty. IET Generation, Transmission \& Distribution.

[81] Balu, K., \& Mukherjee, V. (2021). Optimal siting and sizing of distributed generation in radial distribution system using a novel student psychology-based optimization algorithm. Neural Computing and Applications, 1-29.

[82] Khonturaev, I., Khasanov, M., Anarbaev, M., Kurbanov, A., Suyarov, A., \& Jalilov, U. (2021). Atom Search Optimization Algorithm for Allocating Distributed Generators in Radial Distribution Systems. In E3S Web of Conferences (Vol. 264, p. 04084). EDP Sciences. 